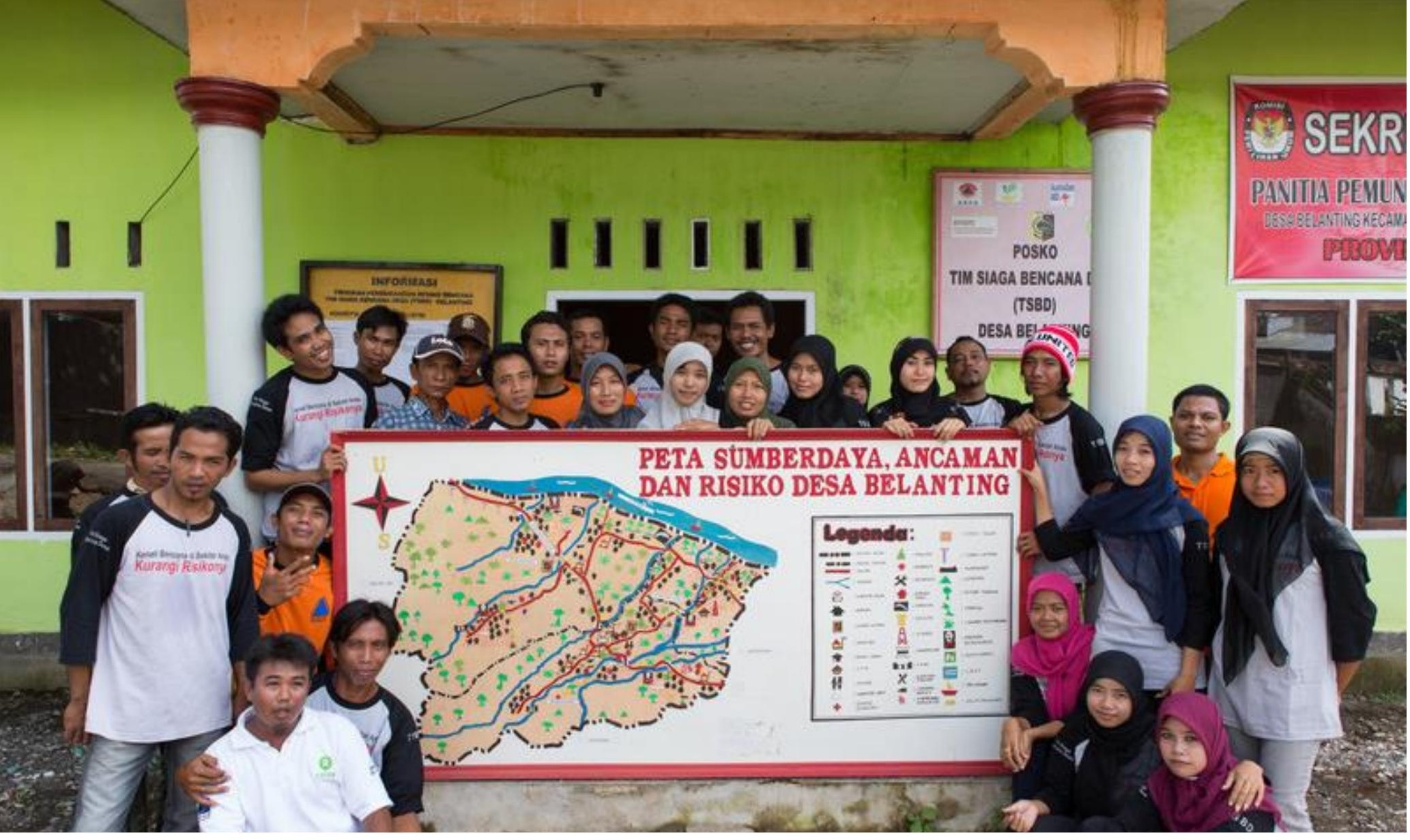

Villagers in Belanting, Indonesia, with a map showing the village's risks, emergency meeting points and evacuation routes. A comprehensive, community-based approach is key for successful risk management. Photo: Rodrigo Ordonez/Oxfam

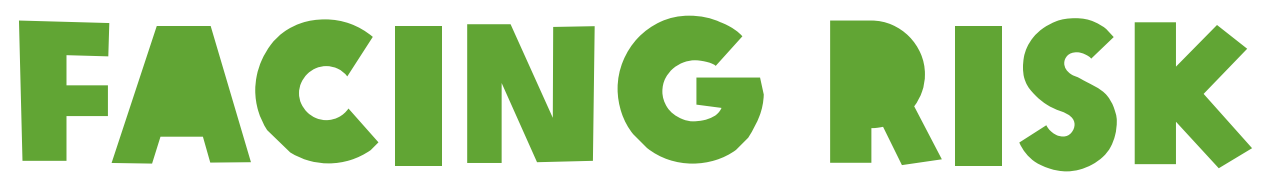

\title{
Options and challenges in ensuring that climate/disaster risk finance and insurance deliver for poor people
}


Reducing the impacts of disasters on poor people is absolutely vital. Climate/disaster risk financing could play a useful role, if it is part of an approach that includes risk reduction, if it strengthens social protection, and has the real participation of civil society. Insurance, as one component of risk financing, could play a supportive role if carefully designed, keeping in mind the limitations, including the risk of worsening income and gender inequality.

The InsuResilience Global Partnership should build more evidence of what works for poor people, invest in pro-poor business models, and ensure the insurance schemes developed are part of a broader approach to reducing risks and the inequalities that make people vulnerable to disasters.

(C) Oxfam International April 2018

This paper was written by Debbie Hillier. Oxfam acknowledges the assistance of very many programme and policy staff across the organization, and external reviewers including Charles Stutley and Richard Carpenter, in its production. It is part of a series of papers written to inform public debate on development and humanitarian policy issues.

For further information on the issues raised in this paper please email advocacy@oxfaminternational.org

This publication is copyright but the text may be used free of charge for the purposes of advocacy, campaigning, education, and research, provided that the source is acknowledged in full. The copyright holder requests that all such use be registered with them for impact assessment purposes. For copying in any other circumstances, or for re-use in other publications, or for translation or adaptation, permission must be secured and a fee may be charged. E-mail policyandpractice@oxfam.org.uk.

The information in this publication is correct at the time of going to press.

Published by Oxfam GB for Oxfam International under ISBN 978-1-78748-225-8 in April 2018. DOI: 10.21201/2017.2258

Oxfam GB, Oxfam House, John Smith Drive, Cowley, Oxford, OX4 2JY, UK. 


\section{CONTENTS}

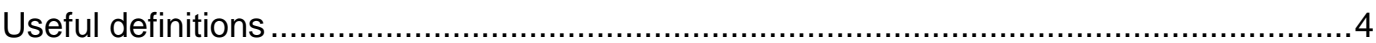

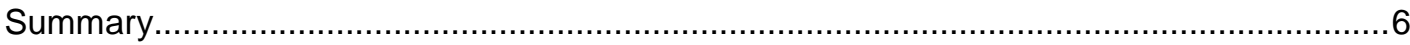

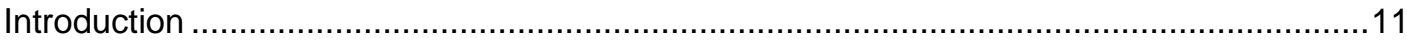

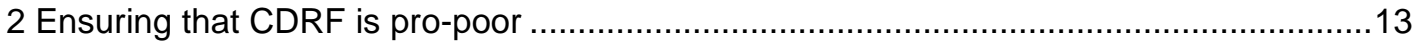

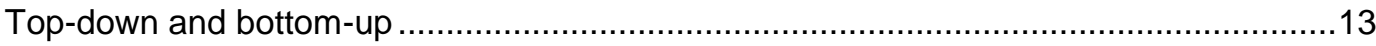

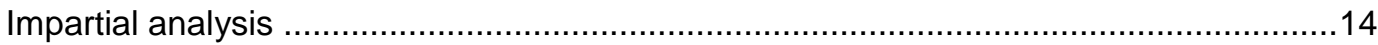

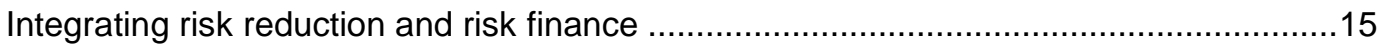

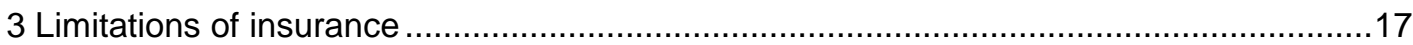

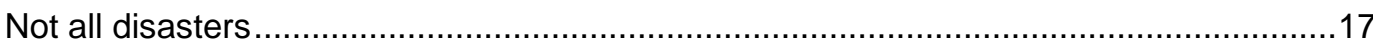

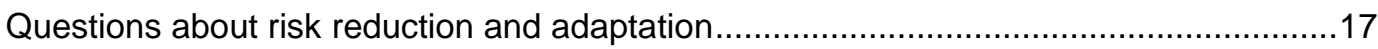

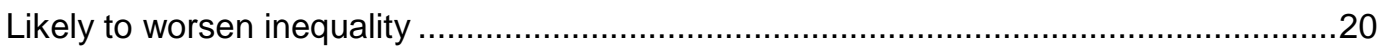

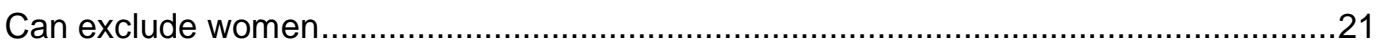

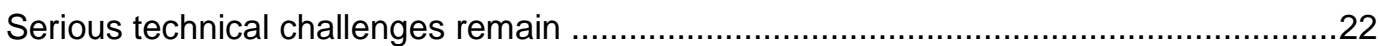

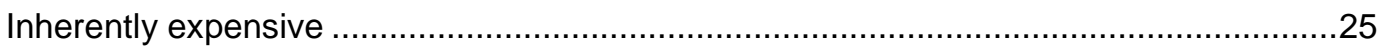

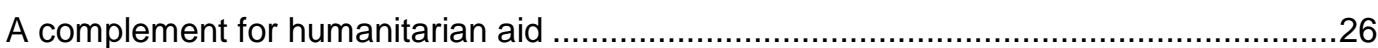

4 Which insurance models could deliver for poor people? ..........................................27

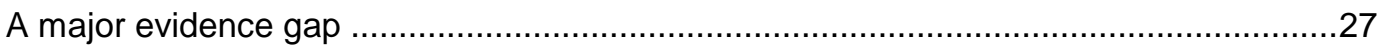

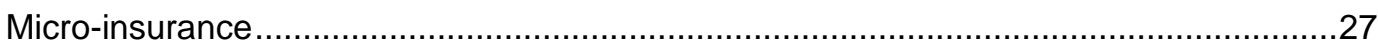

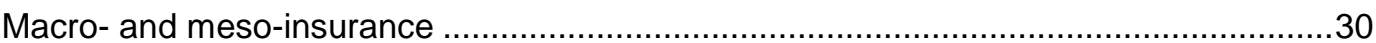

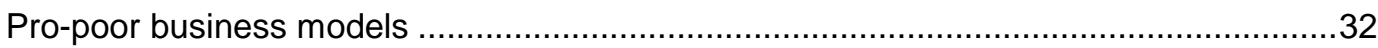

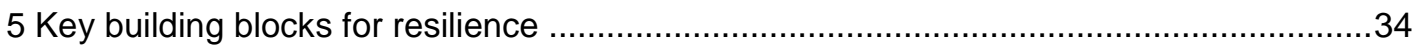

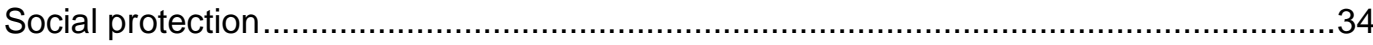

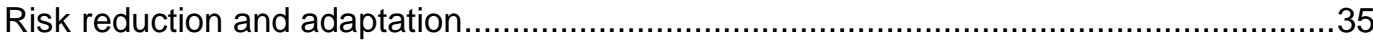

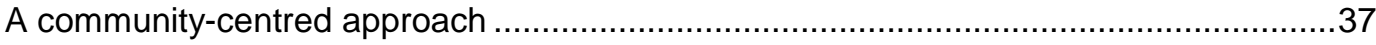

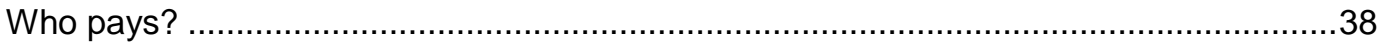

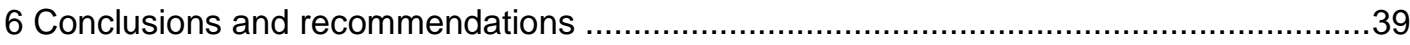

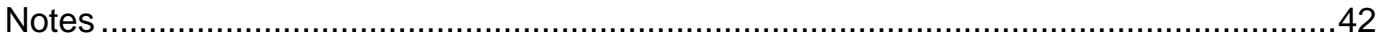




\section{USEFUL DEFINITIONS}

\section{Disaster risk management terms}

Risk management: the identification, assessment and mitigation of risks. The mitigation may involve one or more of risk reduction, risk financing, risk transfer, risk sharing or selffunded risk retention.

Risk reduction: actions taken to reduce the probability or impact of an event, or to reduce exposure.

Risk financing or climate/disaster risk financing: the process of managing risk and the consequences of residual risk through financial products such as contingency funds, insurance, catastrophe bonds (CAT bonds), etc.

Risk transfer: shifting the burden of financial loss to another party, through insurance, reinsurance, legislation or other means.

Risk sharing: the cost of meeting the loss is shared among all participants (as is any profit).

Retained or residual risk: a party retains the financial responsibility for loss in the event of a shock.

Risk layering: separating risk into tiers to allow for more efficient financing and management of risks. High-probability, low-consequence events may be managed by savings or contingency funds. Lower-probability/higher-consequence events may be transferred to the markets. Low-probability/high-consequence events may need aid.

Resilience: Oxfam defines resilience as the ability of women and men to realize their rights and improve their well-being despite shocks, stresses and uncertainty.

\section{Climate/disaster risk financing (CDRF) terms and measures}

CDRF measures: the different financial mechanisms that can be used, such as contingency funds, contingent credit, insurance etc.

InsuResilience Global Partnership (IGP): an initiative launched in November 2017 to stimulate and support CDRF measures.

Insurance: an arrangement by which a company or the state undertakes to provide a guarantee of compensation for specified loss or damage, in return for payment of a specified premium.

Contingency funds/emergency reserves/savings: funding put aside by governments or households for disasters.

Contingent credit: a donor or bank pre-commits to provide credit, usually to a government, when a disaster threshold is triggered, often on concessionary terms.

Catastrophe bonds: investors provide capital and receive interest, but if the disaster threshold is triggered, the principal does not have to be repaid and is used to provide liquidity for the disaster response.

Forecast-based financing: pre-agreed funding provided for specific actions when specific triggers are met. 


\section{Insurance terms}

Micro/meso/macro insurance: where the policyholder is an individual/risk aggregator such as a microfinance institution, cooperative or government.

Indemnity insurance: where the payout to the insured party is matched precisely to the loss, as measured by professional loss adjusters.

Index or parametric insurance: where payouts are triggered by a pre-agreed index and, once triggered, the amount of the payment is determined by the index.

Basis risk: the risk with index insurance of a difference between the payout, determined by the index/model, and actual losses.

Premium: the (often annual) cost of an insurance policy.

Deductible/excess: the loss that the insured party has to bear before the policy will pay out.

Moral hazard: when the insured party's behaviour can influence the extent of damage that qualifies for payouts - such as carelessness, fraudulent claims and irresponsibility.

Reinsurance: insurance taken out by an insurer who is unwilling or unable to carry all the risk.

Mutuals: organizations that provide insurance and other financial services on the basis of risk sharing, not for profit.

\section{A few acronyms for key insurance schemes}

$A R C$ : African Risk Capacity

CCRIF: Caribbean Catastrophe Risk Insurance Facility

PCRAFI: Pacific Catastrophe Risk Assessment and Financing Initiative 
Disasters resulting from natural hazards are becoming more frequent and more harmful. They push an estimated 26 million people into extreme poverty each year. ${ }^{1}$ They also drive increasing inequality, as poor people are hit hardest and find it far harder to recover than wealthier people. For all these reasons, the goal of reducing the impact of disasters on poor people is absolutely vital. This report asks if and how the international investment on climate/disaster risk financing (CDRF) and climate/disaster insurance (not other forms of insurance such as health or life cover) can contribute to this.

In 2015, the G7 agreed a target to provide climate risk insurance for 400 million more poor and vulnerable people in developing countries by 2020 , and this has now developed into the InsuResilience Global Partnership (IGP). In less than three years, $\$ 715 \mathrm{~m}$ has been raised, the vast majority of it to support insurance schemes. ${ }^{2}$

Our rapidly warming world suggests a focus is required on proven solutions. There is still, however, relatively little empirical evidence that insurance is effective in supporting poor people in the face of disasters. Well over 100 disaster insurance schemes targeting lowincome populations have been set up around the world, ${ }^{4}$ yet remarkably few evaluations have considered their impact. ${ }^{5}$ It could well be argued that the InsuResilience target on quantity - without an equally clear focus on quality - is premature.

\section{OPPORTUNITY COST}

With limited public funds available, investing in one area inevitably means investing less in others. And this becomes even more relevant as insurance schemes for poor people are likely to require public subsidies for the long term and possibly indefinitely. This focus of public expenditure on insurance could therefore potentially jeopardize effective and proven risk management approaches.

For example, social safety net programmes are proven ways to support poor people through the shock of disasters. In 2017, a meta-evaluation covering 27 safety net programmes in 14 African countries found strong evidence of increases in food and other consumption, and in livestock and productive assets, as well as incomes and earnings. ${ }^{6}$

Measures to reduce the risk of disasters and to adapt to climate change are also both effective and cost-effective. For example, one analysis found that 102 out of 117 disaster risk reduction (DRR) programmes were cost-effective, with higher impacts for those in less developed countries; ${ }^{7}$ another found that early warning systems could yield benefits 4 to 36 times greater than the cost. ${ }^{8}$ Yet both DRR and climate change adaptation (CCA) remain critically underfunded.

The $\$ 715 \mathrm{~m}$ that has been put into InsuResilience work is about as much as international donors spend on DRR every year. So, while recognizing that innovative approaches will be needed, it is a legitimate question to ask where limited public resources are best channelled. Is enthusiasm for insurance, including the InsuResilience target, skewing efforts and diverting investment from better-established and proven interventions that would probably make a better job of reducing the risks faced by the world's poorest people?
'Insurance will not make crops grow. Incorporating risk reduction mechanisms such as weeding, irrigation and recommendations for planting at the right time can be combined with insurance.'

Rahab Kariuki, Managing Director, ACRE Africa ${ }^{3}$ 


\section{KNOWING THE LIMITS}

This does not mean that there is no role for insurance in dealing with the risk of disasters.

But far greater investment is required in monitoring and evaluation (M\&E) for impact, analysis on the factors that make access to insurance fair and for everyone, and in research on the alternatives and opportunity costs involved. In the meantime, a more balanced dialogue is needed around the potential for insurance and recognition of some of the limits and the unknowns.

For instance, a rule of thumb for practitioners is that disaster insurance is not likely to be cost-effective for disasters that occur more frequently than about once in seven years. ${ }^{10}$ Nor can insurance be used to manage the slow rise in sea levels or any other gradual effect of climate change that is a tragic certainty rather than a risk. And yet poor people suffer enormously both from these slow certainties of climate change, and from frequent disasters that strike every year or two.

Further, despite the potential, there is little evidence that insurance incentivizes risk reduction, and there is mixed evidence on adaptation. Paradoxically, indemnity insurance for infrastructure is unlikely to foster 'building back better', a principle of effective aid after disasters since at least the 2004 Indian Ocean tsunami.

Insurance can also increase inequalities - as without substantial and well-targeted subsidies, poorer people are likely to be excluded from micro-insurance schemes (where the individual is the policyholder) due to affordability, political, social or economic marginalization or other reasons. Many schemes are gender-blind, such that schemes may exclude women or increase household inequalities.

Crucially, 'basis risk' (the difference between an insurance payout and actual losses), which is a key problem for index insurance, means that insurance schemes may not reduce financial risk at all. When considering the opportunity cost of the premiums, people or governments could even be worse off.

\section{PRO-POOR INSURANCE}

Standalone microinsurance seems not to be appropriate for the poorest people, who have many risks, little income and few assets to insure. It may be a solution to prevent vulnerable people from falling into poverty due to shocks, but more work is needed to identify the income or asset threshold for success. As weather hazards are not the only risk poor people face, a deeper understanding of the root causes of vulnerability must be the starting point. Integrated approaches that combine insurance with measures to address other constraints (such as credit or risk reduction) - like R4 and Nataal Mbay - offer more promise.

Macro- and meso-insurance models (where the government or a 'risk aggregator' such as a cooperative is the policyholder) seem to offer potential, especially if they are integrated into broader programmes to increase resilience. But to ensure that payouts swiftly reach poor people, more investment is needed to develop effective contingency plans, delivery mechanisms and targeting.

Finally, business models need to be found that can better meet the needs of poor people: both adding in the missing ' $p$ ' in public-private-people partnerships to rebalance the roles and interests of all parties, and supporting mutuals and cooperatives which are often uniquely placed to support poor communities.
'We should be investing more in prevention. Firstly because you save lives, and secondly you save money.'

Enrique Guevara, former head of Mexico's National Center for Disaster Prevention, CENAPRED ${ }^{9}$ 


\section{A WAY FORWARD}

The world's development, adaptation and humanitarian systems are almost overwhelmed by the scale of the challenges they face, so investment in innovation is required. But this must be underpinned by a strong commitment to learning, ensuring that results from increased investments in impact measurement swiftly find their way into programme development. It should not come at the cost of proven risk management strategies, particularly in a rapidly warming world.

There is an argument that insurance could be a useful tool for middle-income people, thereby freeing up government and donor resources for people in poverty. While attractive in principle, the lessons from health insurance are that this leads to a stratification of services and support, such that inequality is deepened further. ${ }^{11}$ Disaster insurance must be designed so as to avoid this.

More broadly, the objective of the CDRF process - to provide better financial management for risks - is clearly positive. But it must be pursued with a clear imperative to protect poor people, be driven by climate justice (a recognition that those most impacted by climate change have done least to cause it and should be supported), and be implemented in combination with measures to reduce risk. Perhaps most importantly, risk-financing decisions of governments should be open to public scrutiny, and made after a meaningful involvement of civil society in affected countries.

For none of these are simply technical processes. They involve decisions about how to respond to the different risks faced by different parts of society - poor and rich, women and men - and whether governments, insurers and donors tackle, ignore or at worst deepen such inequalities.

Insurance schemes cannot of course answer the whole challenge of reducing the vast human needs of disasters - payouts from regional insurance pools have been small in relation to the sums sought in UN humanitarian appeals - but well-designed schemes could complement aid if funding can be found. To meet the promise of the Sustainable Development Goals, agreed in 2015, to 'leave no one behind,' this must be married with a greater investment in social protection and safety nets, and a broader approach to reduce risks and adapt to climate change.

\section{'People's own determination to get out of poverty should be matched by our commitment to redistribute risk and build equality, thereby supporting them to thrive and prosper, rather than just cope and survive in a world of increasing risks.'}

HE Ellen Johnson Sirleaf, former President of Liberia ${ }^{12}$ 


\section{KEY RECOMMENDATIONS}

\section{Donors and governments should ensure that protection is provided for the poorest people}

- Ensure that social protection and safety nets are available to protect the poorest people, funded by progressive taxation ${ }^{13}$ and international aid. CDRF measures could play a role in funding shock-responsive systems.

- Prioritize risk reduction and adaptation to reduce the risks that poor people face. Public investment in CDRF should not disincentivize or otherwise crowd out investment in DRR or CCA. Use the World Bank's well-being metric, or similar, to identify an appropriate package of measures that delivers for poor people. ${ }^{14}$

IGP partners should identify the right balance of CDRF priorities

- Ensure that the target to reach 400 million people with insurance does not skew programme responses. The IGP should provide a) impartial technical advice and b) funding for the full range of CDRF and risk reduction tools, not just insurance, considering forecast-based financing, contingent credit and grants, resilience bonds, and so on.

- Develop pro-poor principles that will guide the work of the IGP, derived from the recommendations in this paper.

- Ensure that supported CDRF schemes are pro-poor and reduce risk: embedded within a strong and comprehensive risk management framework; explicitly seeking to incentivize and enable risk management and avoid maladaptation; and having clear contingency plans, delivery mechanisms and targeting protocols.

\section{All stakeholders should ensure that CDRF and insurance schemes are demand-led}

- Provide much clearer objectives, success criteria and indicators on reducing the vulnerability of affected populations.

- Foster schemes that are nationally and locally driven, by both government and affected communities. Support full participation of affected communities and capacity building and financial support for Southern civil society organizations.

- Provide support for the delivery of insurance through cooperatives, mutuals and selfhelp groups, including appropriate regulation and support for federation and reinsurance.

- Support public-private-people partnerships, balancing the roles and interests of all parties to achieve effective outcomes.

- Ensure accountability and transparency. Support stronger national regulatory and parliamentary oversight, and the IGP should set up an independent facility where concerns can be registered and complaints investigated.

Where insurance is being considered, all stakeholders should consider the root causes of vulnerability and inequalities

- Analyse the root causes of vulnerability that drive risk, including structural inequalities affecting women and girls, older people, people with disabilities and marginalized and vulnerable groups.

- Prioritize options which achieve a more balanced distribution of risk across society, and ensure that measures to address power and inequalities are incorporated or provided alongside insurance.
'There are so many risks, resulting in so many emergencies, that it is unrealistic to expect poor households to contain them by means of the single financial strategy of insurance.' 
- Commit to improving gender equity through the development of a gender framework, using disaggregated data, gender-sensitive design and further research to increase impact and avoid unintended consequences that may deepen existing inequalities.

\section{The IGP should support learning and increase programme quality}

- Build evidence, undertake research and focus on learning to stimulate an informed and nuanced debate and improve programme quality. The research agenda should include work to identify those for whom insurance is an effective and cost-effective option (and those for whom it is not), more work on opportunity cost and alternatives and development of insurance schemes that support adaptive capacities.

- Radically increase funding and strengthen monitoring and evaluation. Rather than focusing primarily on counting coverage (to achieve the target of 400 million people), M\&E should focus on developmental impact, including social and ecological consequences, both intended and unintended, and any maladaptation. A minimum of $5 \%$ of programme spend should be invested in M\&E

- Develop tools for the sector. The IGP should develop and/or promote minimum programme standards, an M\&E framework, a gender analysis tool and other tools to ensure impact as well as sustainability.

\section{All donors should support climate justice}

- In line with UN Framework Convention on Climate Change (UNFCCC) obligations, donors should provide sustained, predictable and long-term financial support for comprehensive disaster risk management and climate change adaptation, which may include CDRF.

- Develop alternative sources of finance for CDRF measures that address loss and damage, such as levies on fossil fuel extraction or revenues from carbon pricing systems, to ensure less reliance on aid.

- Request evidence from insurance company partners that they do not drive climate change through other investments in fossil fuels and other high-emission sectors or, at the very least, that there is a time-bound plan to phase out such investments as soon as possible.

\section{Oxfam insurance programmes}

This report has been informed by Oxfam's work on insurance.

- The biggest and best-known is the R4 Rural Resilience Initiative, a partnership between Oxfam America and the World Food Programme (WFP). The programme is most established in Ethiopia and Senegal and WFP is expanding the programme to Malawi, Zambia, Kenya and Zimbabwe. It is targeted at the very poor and consists of a package of measures: risk reduction (DRR), risk transfer (insurance), risk reserves (saving) and supporting prudent risk taking (credit). It enables poor people to pay for their insurance through social protection work schemes.

- An innovative meso-level flood index scheme in Bangladesh is providing business interruption cover to very poor landless men and women who are reliant on wage labour. This was suspended for a while due to lack of funds; it is now operational again, but still needs to scale up.

- Schemes are being developed in the Philippines (a meso-level scheme for municipalities), Nepal (livestock) and Sri Lanka (crops), and others are at exploratory stage in Pakistan, Burkina Faso and Vietnam. 


\section{INTRODUCTION}

Disasters resulting from natural hazards are becoming more frequent and more harmful. They push an estimated 26 million people into extreme poverty each year. ${ }^{17}$ The vast majority of disasters are related to climate $-87 \%$ of them in the decade to $2014 .{ }^{18}$ In 2017 there was a series of devastating disasters in various parts of the world: Hurricanes Harvey, Irma and Maria, deadly heat waves in India, drought in the Horn of Africa and flooding in South-East Asia. Disasters from natural hazards have caused the death of 54,000 people, affected 97 million others, and led to economic losses of $\$ 27 \mathrm{bn}$ on average per year. ${ }^{19}$

Vulnerable and poor countries are most affected by disasters and bear the brunt of worsening climate change. People lose their lives, homes, jobs, security, as well as their income and productive assets, with longer-term impacts on health, education and hopes of getting out of poverty. And within poor countries, it is the poorest people who are most likely to be affected, as they live in the most marginal and risk-prone environments.

The human impact of disasters is often huge. Yet humanitarian aid usually covers only a fraction of the impact (estimated at $8 \%$ of total losses); ${ }^{20}$ governments and households inevitably shoulder much of the cost. Unforeseen and therefore unbudgeted expenditures after a disaster can cut deep into developmental projects, diverting expenditure and increasing debt. This in turn can increase inequality and poverty.

Against this backdrop, climate/disaster risk financing (CDRF) has gained momentum, and insurance, in particular, has received a lot of interest. The OECD has provided a steady stream of guidance; ${ }^{22}$ the World Bank's Disaster Risk Financing and Insurance Program has provided assistance in more than 50 countries; ${ }^{23}$ pilot insurance schemes at all levels have proliferated, funded by donors including the UK, Germany, the US, Switzerland and Japan; and insurance is the most dynamic aspect of loss and damage within the UN Framework Convention on Climate Change (UNFCCC) - at least from the perspective of developed countries.

In 2015, the $\mathrm{G} 7$ agreed a target to provide insurance for 400 million more poor and vulnerable people in developing countries by 2020. In July 2017, the G20 endorsed the creation of a partnership in this field, which was duly launched in November 2017, as the InsuResilience Global Partnership for Climate and Disaster Risk Finance and Insurance Solutions, or the IGP for short.

The IGP's stated objective is to 'enable more timely and reliable post-disaster response through the use of climate and disaster risk finance and insurance solutions, thereby reducing humanitarian impacts, helping poor and vulnerable people recover more quickly and strengthening local resilience over time'. ${ }^{24}$

As the IGP is newly launched, it is not clear yet how this objective will be met in practice. While it suggests that the IGP will cover all CDRF options, the vast majority of the $\$ 715 \mathrm{~m}$ raised under the InsuResilience name is for insurance, ${ }^{25}$ and efforts so far seem to be focusing primarily on insurance delivered through public-private partnerships, through mechanisms such as the InsuResilience Investment Fund and InsuResilience Solutions Fund. ${ }^{26}$ 
The enthusiasm for insurance seems to be somewhat out of step with the (lack of) evidence. The unfortunate reality is that to date more than 100 unsubsidized microinsurance schemes have failed ${ }^{27}$ and other schemes have failed to reach their potential. This paper takes a closer look at issues and challenges around CDRF and insurance and seeks to answer the question of whether and how they can be a part of the solution for poor people. It does not consider insurance for wealthier countries or people.

There is no single, universal definition of poor people, but the InsuResilience target group is defined as follows: ${ }^{28}$

- extremely poor: people living on less than $\$ 1.90$ PPP/day 29

- moderately poor: people living on \$1.90-3.10 PPP/day

- vulnerable: people living on \$3.10-15 PPP/day.

\section{Box 1: What is climate/disaster risk financing?}

Climate/disaster risk financing is the process of how to manage the financial consequences of a shock caused by natural hazards. This entails undertaking a careful analysis of the historical costs of disasters, the risk of future disasters and an exploration of what the most appropriate financial mechanisms would be to manage these costs.

The most common CDRF mechanisms for governments include:

- contingency funds or emergency reserves - funding put aside at national or other levels of government to fund disaster response;

- contingent credit - pre-arranged credit, from donors or multilateral banks, often at a preferential rate, released when an emergency is declared;

- catastrophe bonds - set up to provide substantial amounts of money from international capital markets after a major crisis;

- agricultural or catastrophe insurance - this is usually index-based, i.e. payouts are triggered when a threshold is crossed, such as rainfall levels, wind speed, average farmer yield, etc.

For insurance, there are a range of options:

- micro schemes, particularly for agriculture or livestock, where farmers or other individuals are the policyholders;

- macro or sovereign schemes where the government is the policyholder. These may be regional risk pools involving a number of countries or national-level schemes;

- meso-level schemes, where a 'risk aggregator' such as a rural bank, microfinance institution or cooperative is the policyholder, and it distributes the payout to its members/creditors.

This paper and the IGP are concerned only with disaster/weather insurance, and not with health, life or other forms of insurance. 


\section{ENSURING THAT CDRF IS PRO-POOR}

Climate/disaster risk financing is the process of identifying the best financial solutions for governments to deal with the costs of disasters. The CDRF process involves undertaking a careful analysis of the historical costs of disasters and the risk of future disasters, identifying governments' 'contingent liabilities' and then developing ways to better manage these liabilities. This usually involves a layering process, with different financial solutions found for different types of disaster: for instance, the cost of frequent/low-level hazards could be met with emergency reserves and/or pre-arranged credit, whereas more infrequent and catastrophic hazards might require insurance and/or aid.

In order to really add value, the CDRF process needs not only to identify the right financial tool (credit, reserves, insurance or other) but also to develop clear plans for how that money would be spent in a disaster - i.e. precisely who the money will benefit and what delivery system or distribution mechanism will be used. Without this key element, there is no guarantee that funding will get to those in need quickly post-disaster.

\section{TOP-DOWN AND BOTTOM-UP}

National-level analysis and strategy development on CDRF, typically undertaken by World Bank experts and ministers of finance, is presented as a very technical exercise - and in many ways it is, involving data and analysis relating to historical and modelled loss, financial impact, cost-benefit, macro-economics and financial management. But it also involves highly political decision making; the first part of the process is for the government to decide how much protection to provide, and to whom. ${ }^{31}$

Framing risk management purely as a technical process ignores the fact that risk does not affect all parts of society equally and that real-world risk management can involve the strategic use of power to leverage opportunity by displacing risks onto others. ${ }^{33}$ As finance is inevitably limited, trade-offs and decisions have to be made that may prioritize economic growth or 'economically productive' areas or sectors (such as commercial centres or commercial agriculture), rather than poor people and smallholder farmers. Such decisions need to be open to public scrutiny. Yet the World Bank's CDRF process does not currently require or carve out space for civil society engagement. ${ }^{34}$

It is perhaps not surprising that much of the work done on CDRF and insurance so far has been rather top-down. This is a technical issue and is also new and innovative, and it requires a certain push from donors and others to overcome initial barriers and structural inertia. Nevertheless, extreme care must be taken to ensure that a somewhat top-down and supply-driven approach is rigorously balanced with a bottom-up perspective, to ensure that the drive for successful CDRF initiatives does indeed meet the needs of those it is aiming to serve.

Participation, transparency and accountability are key to ensure that the priorities of vulnerable communities are reflected and the needs of those suffering the impact of disasters are met. A positive and progressive engagement with civil society will strengthen outcomes, and in some places this may need to be actively fostered (for some promising examples, see Box 2).

\author{
'Farmers' \\ interviews in the \\ Philippines \\ showed their top \\ concern is the \\ high price of agro \\ inputs, while \\ weather risks \\ were not \\ mentioned, \\ despite frequent \\ natural hazards.' \\ Jimmy Loro, GIZ-RFPI \\ Asia $^{32}$
}


What is important is listening to affected communities. 'Inclusion' does not only mean a seat at the table or being allowed to pick from a fixed menu of solutions - this can be a way of legitimizing the injustice of existing practices and reproducing fixed roles and power positions. ${ }^{35}$ Rather, it must be a genuinely open exercise.

\section{Box 2: Increasing transparency - examples from Bangladesh and Kenya}

In the past 10 years, the Government of Bangladesh has taken a range of positive and proactive measures to address climate change, in particular the Bangladesh Climate Change Strategy and Action Plan in 2009 and the Climate Change Trust Act in 2010. The latter agreed to set aside a fund of $\$ 100 \mathrm{~m}$ per year for several years, two-thirds of it for adaptation and one-third for disaster response. While some projects have been extremely successful, there has been criticism around corruption and a lack of local-level risk assessment, and whether plans prioritize activities to help the most vulnerable people. ${ }^{36}$

In response, the Climate Finance Transparency Mechanism is being established. The goal is to increase the efficacy of climate change funds in tackling the impacts of climate change in Bangladesh, through analysing and processing information on both fund receipt and disbursement and making it available and accessible. This will strengthen accountability to citizens directly and will enable parliament to hold the executive to account. ${ }^{37}$

In Kenya, Transparency International and Germanwatch have recently begun a project with the objective of strengthening civil society engagement and developing a multi-actor partnership to promote a human rights-based approach in the work of the African Risk Capacity (ARC). This will build civil society capacity and develop an analytical framework for ARC contingency plans based on pro-poor and human rightsbased principles.

\section{IMPARTIAL ANALYSIS}

Alternative CDRF options should be analysed on their merits, without any preconceptions about specific schemes or mechanisms. In other words, the CDRF process needs to be impartial. There is a danger that the political drive to achieve the InsuResilience target to provide climate risk insurance to 400 million additional poor and vulnerable people could skew international efforts to protect people from worsening climate and disaster risks, if it is not proactively complemented with other approaches.

There may be some way to go before an impartial approach is achieved in practice. An evaluation of the Caribbean Catastrophe Risk Insurance Facility (CCRIF) found that it was 'supply-driven in the sense that the insurance solution was the modality on offer when [programme objectives] seemed to invite a broader, demand-driven approach'. ${ }^{39}$ Similarly, the ARC Agency provides a valuable service to African governments to increase understanding of risk through the development of a customized model, capacity building and contingency plans, yet currently the only financial solution offered to help governments respond to this risk is insurance, and not a suite of different and integrated responses.

One study found that countries with high insurance penetration bounce back more quickly economically after disasters. ${ }^{40}$ But this study tells us nothing about the costs of the insurance policies, and whether alternative uses of that money would have had more impact. 
The review of different disaster financing options needs to incorporate an estimate of costs and opportunity cost. For insurance schemes aimed at poor people, there is a growing recognition that subsidies will be required, for a long time and potentially permanently. Analysis is required to estimate whether this is the best use of public money. And rather than purely subsidizing insurance, there may be higher demand for well designed, transparent insurance projects, complemented with risk-reduction measures. ${ }^{41}$

It is hard to find comparisons of different options and specific details matter - thus it is not possible to be clear on opportunity costs. However, we do have a few illustrative comparisons:

- In an early analysis, ARC was expected to cost $\$ 1.50$ for every $\$ 1$ delivered, due to setup costs, capitalization of the scheme, management costs, reinsurance profits, etc. For one-in-five-year events, ARC would represent worse value for money than a regular budget allocation, i.e. a national contingency fund..$^{43}$ (A new cost-benefit analysis has just been commissioned.)

- In Kenya, both livestock insurance through the Index-Based Livestock Insurance (IBLI) scheme and social protection through the Hunger Safety Net Programme (HSNP) have positive impacts. Considering total costs to date per beneficiary, the two programmes are comparably cost-effective at their current scale. But for scale-up - the marginal cost of additional clients - IBLI is an order of magnitude more cost-effective, reflecting the relatively large sunk costs of developing and marketing a new product. ${ }^{44}$

There is a real need for more research on the costs and benefits of alternatives, and on the opportunity costs of insurance.

\section{INTEGRATING RISK REDUCTION AND RISK FINANCE}

A comprehensive approach to risk management is required, where risks are assessed and the most appropriate solution is found. For example, when faced with flood risk, a solution might be to ensure that vulnerable people have insurance against flooding, or the government has a line of credit available for response, but other risk reduction and adaptation options could include strengthening flood defences, implementing construction and planning controls or providing early warning and evacuation systems.

\section{DEVELOPING COMPREHENSIVE STRATEGIES}

A clear-sighted analysis of all of these options and others needs to be undertaken, and the optimum solution is likely to be a combination. For example, a study considering the costs and benefits of different risk management options for drought in Maharashtra, India, finds that about $80 \%$ of expected losses can be covered by a portfolio of risk reduction measures (such as watershed management and rainwater harvesting) and insurance is required to offset the impacts of high-severity events. ${ }^{45}$

Risk reduction has to go hand in hand with risk transfer - the cost of full insurance protection would be prohibitive without policy measures and investments to address the causes of risks and to mitigate vulnerabilities. ${ }^{47}$ Risk reduction measures will help to make insurance more accessible, affordable and viable in the long run. For example, one study found that improvements in irrigation for maize production in Mozambique would reduce insurance costs by at least $30 \% .{ }^{48}$
'We need to consider what

we are promising with agricultural index insurance, and if we can deliver on those promises.'

Miguel Solana, Impact Insurance Facility, ILO ${ }^{42}$

Vincent Mutie Nzau,

Senior Economist,

National Treasury of Kenya $^{46}$ 
Thus CDRF schemes should be embedded within a strong and comprehensive risk management framework. Yet there is little evidence that the World Bank, a key player in both CDRF and disaster risk reduction (DRR), currently seeks real integration of these two approaches; ${ }^{49}$ teams that design and deliver risk finance and risk reduction are separate and may not exploit the co-benefits or ensure that strategies are joined up.

Within governments, CDRF is often led by the ministry of finance, whereas responsibility for DRR is situated in a dedicated authority to deal with disaster management (e.g. the National Disaster Management Authority in India) and it is then implemented by different line ministries - agriculture, water, etc. Without specific efforts to integrate this work, agencies may operate in parallel. ${ }^{50}$

In fact, there are some good models for how this integration can happen. ASEAN's disaster risk financing programme specifically aims to link DRR with CDRF: it has set up a standing committee involving representatives from ministries of finance, insurance regulators and disaster management authorities. Similarly, in the Philippines, the National Disaster Risk Reduction and Management Council is an inter-agency body, with representatives from finance, risk reduction and line agencies.

\section{RISK REDUCTION IS THE BEDROCK}

In both of these cases, risk financing has grown out of strong pre-existing risk reduction programmes, not the other way around. Even in countries with experience in this area, such as the Philippines and Mexico, challenges remain. ${ }^{51}$ Where CDRF measures have been superimposed on weaker DRR systems, or treated as standalone solutions, there is a risk of creating a false sense of security, and it may not be the most cost-effective solution. For instance, Malawi has had two drought insurance policies (now both discontinued), while at the same time having no DRR budget and no emergency reserves.

Some risk transfer measures - such as insurance and catastrophe bonds - are complex, requiring a high level of sophistication in systems and capacities as well as strong political support. These solutions are unlikely to be effective in countries that do not have established disaster risk management programmes. Even in Peru, it took six years and several failed attempts before the government managed to set up an agricultural insurance scheme. ${ }^{53}$

The basics - of DRR strategies and funds and emergency reserves - should be in place before looking to develop more complex schemes like insurance. Several countries (such as the Dominican Republic, ${ }^{54}$ Mauritania, Malawi and Kenya) ${ }^{55}$ do not yet have successful DRR strategies or budgets, while others have contingency funds that have been set up but are still empty (including Lesotho, Mali and Pakistan) ${ }^{56}$ or in practice are used for any crisis, and hence are unreliable. ${ }^{57}$

More efforts are required to, at a minimum, dovetail and ideally integrate risk finance and risk reduction measures.

\section{'Insurance is only part of the puzzle of disaster risk management. Stakeholders must be open and transparent about the expectations and the possibilities.'}

Andrea Camargo, Microinsurance Catastrophe Risk Organisation (MiCRO) ${ }^{52}$ 


\section{LIMITATIONS OF INSURANCE}

While proponents of insurance are careful to say that it is not a panacea, there is still a lack of nuance about if, how and where different models of insurance can reduce the impact of shocks on poor people. This section explores some of the limitations of insurance.

\section{NOT ALL DISASTERS}

Insurance has a specific role and, as with all things, must be used in the right way to maximize benefit. Insurance is not suitable for all disasters - this is an obvious and uncontroversial point, but it needs to be understood.

A rule of thumb for practitioners is that disaster insurance is not likely to be cost-effective for disasters that occur more frequently than about once in seven years. ${ }^{58}$ However:

- Poor people are often significantly affected by so-called 'extensive disasters': disasters that happen frequently (e.g. every year or two years) and which might be fairly localized, and would not be suitable for insurance.

- Some insurance schemes, such as ARC, are in fact being used for one-in-five-year disasters because of the political reality of countries needing to receive relatively frequent payouts to maintain engagement in the scheme. This means that insurance is expensive.

Further, insurance cannot be used for all hazards. Slow-onset impacts of climate change such as rises in sea level and ocean acidification - cannot be insured, as these are certainties not risks.

Finally, as climate change continues to bite, making disasters more frequent and more severe, the costs of insurance will inevitably rise, potentially out of reach for poor people.

\section{QUESTIONS ABOUT RISK REDUCTION AND ADAPTATION}

Insurance spreads the cost of risk, so rather than suffering one huge loss when a disaster strikes, policyholders make regular smaller premium payments. Thus financial risk is managed and reduced, but the risk of the hazards remains the same.

\section{RISK REDUCTION AND “BUILD BACK BETTER”}

Advocates posit that insurance instils 'risk discipline' and incentivizes risk reduction, and there is good experience of this in developed countries but less in developing ones. For example:

- One study reviewing 27 flood insurance schemes found that 'very few schemes show a direct operational link or an indirect association between risk transfer and risk reduction, and where identified, the evidence for success and effectiveness is extremely limited'. ${ }^{59}$ 
- For regional risk pools, the process of working with governments to explore risk, and insurance as one solution, could plausibly lead to better risk management. However, no evidence has yet been provided in the case of either CCRIF60 or ARC. ${ }^{61}$

One further important issue is that indemnity insurance, which might be used to cover infrastructure losses, is usually based on 'like for like' replacement, i.e. it provides for rebuilding the same infrastructure with the same risk profile. The insurance principle of 'no betterment' means that, by design, it cannot enable 'build back better'. ${ }^{63}$ Paradoxically, therefore, insurance can perpetuate risk and inhibit long-term adaptation, as recovery is prioritized over prevention. Successful schemes have to circumvent this problem; the FONDEN scheme in Mexico offers an interesting model (Box 3).

\section{Box 3: Incentivizing 'build back better' in Mexico}

The Mexican disaster management system has evolved over 20 years into a highly sophisticated and multi-layered programme, including budget reserves at state and federal levels and the use of insurance and catastrophe bonds. FONDEN, Mexico's Fund for Natural Disasters, was established to support the rapid rehabilitation of federal and state infrastructure affected by adverse natural events. There is also a small fund, the Federal Fund for the Prevention of Natural Disasters (FOPREDEN), for risk reduction.

To incentivize building back better, FONDEN does not provide endless resources for reconstruction. For example, for an uninsured federal asset, the fund will provide $100 \%$ of the reconstruction costs the first time it is hit by disaster, but only $50 \%$ for the second time, and nothing for third and subsequent disasters. ${ }^{64}$

Although the insurance itself does not allow 'betterment', the Mexican government provides specific funds for this work. When a disaster strikes, the state government is asked to provide estimates to the FONDEN Technical Committee of the costs of pure replacement and the increased costs for improvements to reduce future disaster damage.

However, funding for risk reduction remains small. Of the total resources available for FONDEN (relief and recovery) and FOPREDEN (risk reduction) from 2004 to 2014, FOPREDEN represented only $0.2-9.3 \%$ of the total, with a general decline in risk reduction spending over this period. ${ }^{65}$ And funding for these schemes has dropped in recent years; in 2017, funding for risk reduction through FOPREDEN was cut by $50 \%$, and FONDEN by $25 \% .{ }^{66}$

Other problems include excessive bureaucratic procedures, diversion of funds, fraud, delays and the failure of aid to reach victims. ${ }^{67}$ And while the Civil Protection Law (2012) and FONDEN rules include the participation of civil society, this is not mandatory. ${ }^{68}$

Other countries could build on Mexico's experience while also increasing the funding available for risk reduction, ensuring that these principles in relation to building back better are realized in full and in practice, and ensuring accountability and transparency around the use of funds.

\section{ADAPTATION AND MALADAPTATION}

Theoretically, insurance could help people to adapt to shocks and stresses. The certainty of knowing that potential losses are covered could improve access to credit, lead to investment in higher risk/reward activities, increase productivity, conserve savings and promote risk reduction behaviour. 
But the evidence is not strong that this is achieved in practice, partly due to the lack of substantive evaluations of insurance schemes. Quite a few models and experimental studies have been undertaken which show some benefit, but their results can be indicative only, as real-world demand and impact has failed to materialize in most cases. ${ }^{69}$

A handful of evaluations of real micro-insurance schemes have found an increase in crop production, and a reduction in the selling of assets or reduced consumption, ${ }^{70}$ such as the PlaNet Guarantee scheme for cotton in Mali and Burkina Faso; and Kilimo Salama for maize in Kenya. ${ }^{71}$ It is difficult to judge this impact on poor people, as most schemes are not specific on the asset/income level or gender of the policyholders. Livestock schemes, such as in Mongolia (see Box 4) and Kenya, seem to offer some promise, although are less successful for poor herders. ${ }^{72}$ This thin evidence base requires strengthening.

These results are in contrast to a particularly robust study from India ${ }^{73}$ that modelled realworld conditions as closely as possible, used randomized controlled methods and monitored impacts over a period of eight years. It found that although insured households benefited financially from the insurance scheme (as overall payouts were higher than premium costs), there was no systematic, long-term effect of access to insurance or its adoption on agricultural investment decisions (e.g. no switching to high-yielding crops) or on agricultural revenues and profits. The insurance payouts had no impact on consumption or savings (as payouts substituted for informal transfers), and there were weak impacts on well-being. ${ }^{74}$

This shows the current dilemma - weak and conflicting evidence on adaptation, and a lack of clarity on if and how lessons from one country or context could be extrapolated elsewhere.

More worrying perhaps than the missed opportunity of risk reduction is the fact that insurance has the potential to undermine DRR and increase maladaptation. ${ }^{76}$ Agricultural insurance may lead to unintended negative impacts on the ecological system, primarily because it incentivizes increased cultivation of (insured) cash crops, leading to overspecialization and monoculture - as has been seen in India, Mali, Mexico and China. ${ }^{77}$ More intensive agriculture can contribute to the degradation of agricultural landscapes and loss of biodiversity and thus reduce resilience to weather-related disasters. While switching to cash crops can have short-term benefits for the individual, it may lead to longer-term ecological costs. ${ }^{78}$ These impacts are clearly unintended, but they cannot be ignored. In a further example from Mexico, insurance reduced investment in irrigation, because farmers were insured only as long as production took place on non-irrigated land. ${ }^{79}$ (The eligibility criteria were subsequently changed to include producers with access to irrigation..$^{80}$ )

We thus find little clear evidence, so far, that standalone insurance for poor people will lead to risk reduction and weak evidence for adaptation. Integrated approaches such as the R4 programme may offer more promise (see Box 6). 


\section{LIKELY TO WORSEN INEQUALITY}

Those who are marginalized - whether socially, politically or economically - face higher risks. These inequalities mean that, for example, some households are forced to live on marginal land or in risky locations, some herders no longer have access to grazing land, small farmers, often women, cannot access water, technical advice and inputs, and so on.

Commercial insurance cannot of course deal with these structural inequalities - that is not its role - but the designers of schemes should be aware of power dynamics in order to not inadvertently favour or exclude certain people, thereby entrenching inequalities further. Where possible, they should seek to redistribute risk by easing the burden on the most vulnerable.

If there is remarkably little in-depth evidence on the developmental impact of insurance schemes, there is even less that even considers the impact on equity. But it is highly likely that insurance by itself will worsen inequality because it excludes the poorest people, due to affordability or other reasons, including geographic location, gender, region or ethnicity. For example, tenant farmers can struggle to access insurance schemes, as can women, who are more likely to be landless; Muslims may be excluded as commercial insurance is not compliant with Islamic religious law. ${ }^{82}$ This differential take-up of insurance will reinforce inequalities unless other protection mechanisms are in place. This was found to be the case for the CADENA scheme in Mexico. ${ }^{83}$

Subsidies can increase access to insurance for poor people. However, they will only support equity where:

- Subsidies are taken up primarily by poor people. Universal subsidies will differentially benefit richer households. ${ }^{84}$

- Government subsidies come from a progressive tax system. In fact, government budgets in developing countries are often largely financed from direct taxes, such as VAT, which are not progressive but are paid disproportionately by poorer households. ${ }^{85}$ This means that poor households contribute relatively more to government insurance premium subsidies than wealthier households. ${ }^{86}$

Further, care should be taken that subsidies benefit poor people rather than insurers; there has been significant criticism in India of the heavily subsidized insurance system, where insurers are perceived to profit at the expense of poor farmers. One study found that payouts to farmers totalled just $40 \%$ of the money paid into the scheme. ${ }^{87}$

And of course, the cost effectiveness of direct subsidy in insurance premiums should be proven to be higher than using the subsidies for other mechanisms, such as disaster risk reduction, work for insurance, programmes to address liquidity issues, or public goods.

There is an argument that insurance could be a useful tool for middle-income people, thereby freeing up government and donor resources for people in poverty. While attractive in principle, the lessons from health insurance is that this leads to a stratification of services and support, such that inequality is deepened further. ${ }^{89}$ And this is certainly what has happened in Mongolia, where the proposed social protection scheme for the smallest herders did not materialize - see Box 4.
'Stop calling me resilient. I'm not resilient. Because every time you say "oh, they're resilient", you can do something else to me.'

'I do not think that we were born to be resilient. You are forced to be resilient when you are placed in an environment that is unnatural with manmade suffering.'

Tracie Washington, New Orleans civil rights lawyer, Louisiana Justice Institute ${ }^{81}$
'Many publicly subsidised index [micro] insurance schemes are little better than a lottery ticket. We can do better.'

Tara Chui, Assistant Director of the Assets and Market Access Innovation Lab, UC Davis ${ }^{88}$ 
schemes, in a worst-case scenario, market-based solutions and the privatization of risk mean that protection becomes a private good for sale, rather than a public good, and available only to those who can afford it. The IGP could have a role to play in ensuring that the development of insurance is framed within the rubric of rights and equity.

\section{Box 4: Mongolian livestock insurance has positive impacts for middle-sized herders}

The Index-Based Livestock Insurance Project (IBLIP) in Mongolia aims to reduce the vulnerability of rural herders to frequent and high livestock mortality rates, which are often due to extreme cold. Small losses (under $6 \%$ of the herd) are absorbed by the herders; medium losses (6-30\% of the herd) are covered by private insurance; and catastrophic loss (over $30 \%$ of the herd) is covered by the national government.

The scheme is often hailed as a success, ${ }^{90}$ and a recent evaluation found a positive impact. ${ }^{91}$ Insured households recovered faster from losses due to an extreme winter than comparable non-insured households, and herd sizes were larger one and two years after the shock.

However, on closer analysis, this evaluation considered only medium-sized herders, because these were the only ones to have taken up the insurance. In fact, this scheme was not aimed at the smallest herders. Initially, its designers proposed a parallel social protection scheme to run alongside IBLIP, but this did not happen.

The result has been that inequality has been exacerbated. ${ }^{92} \mathrm{~A}$ detailed study looking specifically at equality aspects ${ }^{93}$ found that losses were to a great extent socially determined, with poorer herders losing a higher proportion of their herds to the same adverse weather conditions compared with their wealthier neighbours. This is because mortality rates are not determined by hard work, good husbandry or entrepreneurial initiative but instead by herders' degree of access to pasture, campsites, shelter, fodder, wells and veterinary services, which in turn is driven by existing social hierarchies.

IBLIP is playing a useful role in protecting middle-sized herders, but small herders are excluded. This example shows that three things are required to understand and address the real impact on the resilience of poor and vulnerable people:

- disaggregated impact evaluations, to be clear about who is benefiting;

- a specific consideration of social equity and power in the development of schemes;

- risk management solutions provided for all people.

\section{CAN EXCLUDE WOMEN}

Women are over-represented among the world's poor and vulnerable people. Although men and women are equally exposed to risks from production and income, women face additional sources of risk - particularly health risks associated with fertility and childcare and shoulder the burden of managing them on behalf of their families. Yet women have fewer economic options and have reduced access to resources, services and decision making power. Therefore in theory, women could benefit disproportionately from improved risk management. ${ }^{94}$

However, there is an extraordinary paucity of research that specifically explores the gendered dynamics of insurance..$^{95}$ This is despite the fact that women and men often control different crops and livestock or are responsible for different tasks, so the impacts of insurance might have strong impacts on gender dynamics. ${ }^{96}$ 
In general, it seems that women are less likely to access agricultural insurance, due to household power dynamics, lack of trust, lack of land ownership, financial constraints, different priorities or lack of access to formal financial services. As one example, female farmers in Senegal and Burkina Faso are more likely to invest in savings than agricultural insurance schemes as the former can protect against a range of risks; for men, it is the reverse. ${ }^{97}$ One successful way of reaching women is through mutuals or cooperatives ${ }^{98}$ (as explored in section 4 below).

The R4 programme (Box 6) is one of the few schemes that explores the impact on gender. It has found particularly positive impacts on food security and production for female-headed households in Ethiopia. ${ }^{99}$ While effects are also positive in Senegal, male-headed households have seen greater increases in production, suggesting the need to work with local institutions to remove barriers that women face in agricultural production. In Senegal, women's decision making increased, as did their ability to save and acquire small loans for income generation. ${ }^{100}$

Currently, many insurance schemes are gender-blind, which means that they are likely to exclude women and could further shift the balance of decision making power and resources towards the male head of household. By contrast, a women's self-help group is more likely to provide benefits for the whole family and support women's empowerment, which could potentially be transformational for household and community gender relations. ${ }^{101}$

It is not sufficient for insurance to increase household income if this simply increases household inequalities. Gender and power analysis are required to provide a richer picture of who is facing daily and regular hazards as well as structural inequality, in order to design schemes that will support gender equality.

\section{SERIOUS TECHNICAL CHALLENGES REMAIN}

In most developing countries, index rather than indemnity insurance is being used. This is primarily because of the huge administrative costs and time required to verify individual losses at household level.

\section{INDEX INSURANCE AND BASIS RISK}

The advantage of index insurance is that it can pay out much more quickly. For example, in Sri Lanka, although a relatively cheap indemnity scheme is available for paddy farmers, it involves cumbersome procedures and farmers have to wait months until loss adjusters visit their farms. Instead of watching their fields lie idle while they wait, farmers would often rather reinvest and replant even though this invalidates their policy. Under a new index insurance scheme, payouts are decided using a rainfall index, and distribution starts within 2-4 weeks of a disaster event. ${ }^{102}$

However, one of the biggest disadvantages of index insurance is basis risk - i.e. the difference between payouts and actual losses. Basis risk has had an impact on all regional risk pools and has caused many micro-insurance pilots to fail (Box 5). By design, using an index that is correlated with but not identical to individual losses is a second-best approach. ${ }^{103}$ There are different kinds of indices; for those that attempt to model losses, this requires a very detailed understanding of the growing needs (heat, rain, soil moisture, soil composition, etc.) of each crop at very particular times in its growing cycle, and highresolution ways of measuring these.

\author{
'Basis risk: it's \\ like a casino, \\ sometimes you \\ win, sometimes \\ you lose, and this \\ will average out.'
}

Quote from an insurer 
The existence of basis risk means that index insurance products may not reduce financial risk at all, and in fact could leave a policyholder worse off, given the opportunity cost of premium payments. Expecting poor and vulnerable people to accept any financial gamble is clearly unacceptable. Denying basis risk incidents, failing to respond quickly and failing to have a pre-agreed process for response - as happened with ARC in Malawi in 2016 compound the human cost.

While basis risk can be minimized through careful product design (e.g. more sophisticated models, increased density of ground weather stations, increased level of detail of satellite data, etc.), it can never be totally eliminated. One promising 'fail-safe' approach, currently being trialled, uses two indices and provides farmers with a complaints system: if enough farmers report losses over a certain threshold, the insurer must undertake an audit. ${ }^{104}$

\section{OTHER CHALLENGES}

Problems with an index can often be worsened when policies cover only a single hazard; in the real world, hazards often come together - for example, a hurricane will come with a storm surge as well as wind and rain. Further, climate change is tilting the baseline, such that historical records are not a good measure of future losses, and this makes basis risk harder to avoid. Even within a single hazard, coverage is often limited by the price that is affordable. ${ }^{106}$

As well as technical problems with the index, there may also be mis-selling or mis-buying, which results in the purchase of an option that means that the insured party is (knowingly or unknowingly) accepting a high level of first loss ('excess' or 'deductible') before the index will pay out. Mis-buying happened in the case of Rwanda, as explained in Box 5.

Basis risk and related problems due to highly constrained coverage are probably the key challenge for index insurance, but there are others that have caused schemes to fail: technical design issues and data-related constraints, inadequate capacity building for local insurance companies, lack of attention to developing distribution channels and creating value chain propositions, lack of investment in creating awareness and a resulting lack of commercial viability. All these have prevented schemes achieving scale - which is crucial for sustainability.

Insurers need to take a more responsible and proactive approach to managing basis risk and other technical challenges; insurance regulators need to play a more active role in monitoring the performance of pilot insurance schemes and in protecting consumer interests; and policy makers must ensure a legal and regulatory framework that protects insured households and fosters development of sustainable pro-poor insurance markets. 


\section{Box 5: Some examples of basis risk}

Basis risk has affected many index schemes, often with disastrous consequences when the products have failed to trigger payouts, despite policyholders experiencing major losses. In some cases, insurers or other stakeholders have been obliged to make 'ex gratia' payouts in order to protect their reputations; others have closed their programmes down, leaving policyholders very aggrieved.

The Solomon Islands withdrew from the Pacific Catastrophe Risk Assessment and Financing Initiative (PCRAFI) after the country experienced flash flooding in March $2014 .{ }^{107}$ Losses were estimated at $9.2 \%$ of gross domestic product (GDP) but no payout was triggered because the disaster was due to a tropical depression, whereas the policy covered only for tropical cyclones. ${ }^{108}$

A severe drought in Malawi in 2016 left 6.5 million people requiring humanitarian assistance, but initially the country's ARC policy did not pay out. ${ }^{109}$ This led to a huge outcry and a technical review, which found problems with the model input data, and a payout was received nine months later. Malawi did not renew its ARC policy.

In Jamaica, flooding in May 2017 caused $\$ 400 \mathrm{~m}$ in damage. However, the CCRIF model estimated damages at only $\$ 100 \mathrm{~m}$, which was below the threshold for payout. ${ }^{110}$ The difference was due in part to the fact that CCRIF policies cover only built-up areas, including damage to infrastructure, and do not cover agricultural losses. ${ }^{111}$

The ACRE micro-insurance scheme in Rwanda was developed to protect farmers' loans for an improved seed and fertilizer package. It was expensive and, after negotiation with the government, the deductible was raised so that the scheme would trigger payouts only in the case of a relatively severe drought. When serious crop losses were experienced in 2013/14 but no payouts were triggered, farmers' unions protested to the government, which put pressure on the providers to make ex gratia payouts. After this, one of the providers, MicroEnsure, pulled out of designing and implementing agricultural weather index microinsurance.

In 2015, the R4 programme in Ethiopia experienced major losses that did not trigger the index. However, it was able to make payments to needy households out of its Basis Risk Fund. An assessment was undertaken for about 26,000 people in 81 villages of Tigray; the time taken for the assessment process meant that payouts were received several weeks later than usual. To reduce the likelihood of basis risk, the index has now been changed in one region, using two indicators rather than one. ${ }^{112}$

In Sri Lanka, Oxfam worked with insurance company SANASA to introduce a new scheme for paddy farmers. In 2016, short bursts of extreme rain damaged paddies but failed to trigger a payout. Oxfam's damage assessment found that nearly $70 \%$ of the insured farmers had experienced crop damage of over $50 \%$, and this was a key factor in getting ex gratia payments from SANASA. ${ }^{113}$ 


\section{INHERENTLY EXPENSIVE}

Insurance is inherently expensive as policyholders are paying a third party to carry the risk - it is therefore not appropriate for frequent risks.

Precise costs will vary from scheme to scheme, but Table 1 shows indicative costs and limitations for micro-insurance. The best solution will be a combination of different financing options - with savings for frequent risks and insurance for less frequent risks.

Table 1: Indicative costs for micro-insurance and alternatives ${ }^{114}$

\begin{tabular}{|l|l|l|}
\hline $\begin{array}{l}\text { For \$1 benefit } \\
\text { from }\end{array}$ & $\begin{array}{l}\text { Approximate } \\
\text { cost in \$ }\end{array}$ & Issues \\
\hline Savings & $0.95-1.00$ & $\begin{array}{l}\text { Flexible - can be used for a range of risks. } \\
\text { Surprisingly, research finds that people living on } \\
\$ 1-2 \text { a day can manage to save 255 of their } \\
\text { income, }{ }^{116} \text { but nonetheless it can be very hard } \\
\text { for poor people to build up savings into a } \\
\text { significant sum, and particularly to set them } \\
\text { aside for a 'rainy day' without using them for } \\
\text { urgent needs. }\end{array}$ \\
\hline $\begin{array}{l}\text { interest rate } \\
\text { on savings }\end{array}$ & $\begin{array}{l}1.25 \\
\text { Assuming } \\
\text { interest rate of } \\
25 \%\end{array}$ & $\begin{array}{l}\text { Flexible - can be used for a range of risks. But it } \\
\text { requires creditworthiness and access to credit, } \\
\text { which can be a challenge. Note that insurance } \\
\text { can support access to credit. }\end{array}$ \\
\hline Insurance & $\begin{array}{l}1.50 \\
\text { Assuming } \\
\text { typical costs of } \\
\text { index } \\
\text { insurance }\end{array}$ & $\begin{array}{l}\text { Will provide funds at the time of a loss. But risk } \\
\text { may not be reduced due to basis risk, or due to } \\
\text { shocks not covered by the policy. }\end{array}$ \\
\hline
\end{tabular}

One interesting innovation from BRAC in Bangladesh is contingent emergency credit that is released in the event of a shock; with a $25 \%$ interest charge, it is cheaper than existing index insurance contracts. ${ }^{117}$ Such contingent credit may not only be cheaper but may also make more sense; research finds that emergency lump sums loans are really important for poor people - they can provide a general cushion for risks, rather than formal insurance which requires each risk to be separately insured and the payment of multiple policies. ${ }^{118}$

In terms of regional risk pools, pooling risk between countries can dramatically bring down the cost of insurance - for instance, PCRAFI has more than halved the cost of insurance for individual countries in the Pacific. ${ }^{119}$ However, even with this cost reduction, according to the World Bank, 'catastrophe risk pools cannot make insurance cheap'. ${ }^{120}$ It is worth noting that developed nations do not have sovereign insurance because they have cheaper options in the form of emergency reserves and borrowing on international markets.

In terms of national schemes, there is little information on costs, except for CADENA, the national insurance scheme in Mexico, where an evaluation found that 'while the cost of insurance appears to be high relative to the payouts, the benefits exceed the costs for a substantial range of outcomes'. ${ }^{121}$
'In the

beginning we thought it would be hard [to create a savings group] because there is no money to save. Then we saw that "little by little, the bird makes its nest". The money was growing and it was only from us!'

Member of Saving for Change group in Mali ${ }^{115}$ 


\section{A COMPLEMENT FOR HUMANITARIAN AID}

The problems facing humanitarian aid in-country (slow, insufficient, uncertain) and for donors (hugely rising costs) are well understood, and have been a significant driver in the search for other solutions, including insurance. What role can insurance play?

A major advantage of insurance compared with aid is speed and certainty of payouts - and CCRIF and PCRAFI perform extremely well on this front, with payouts being received in a matter of days. (But note that basis risk can destroy both of these advantages, and payouts to household level from ARC so far have been very delayed in all but one case. ${ }^{122}$ )

There is real hope that insurance can start to substitute for humanitarian aid, and the potential is there, but the premiums need to be paid from somewhere. The size of the payout is dictated by the premium paid, which in turn is limited by willingness and ability to pay by either the country or a donor. So far, payouts have been small in relation to humanitarian need (Table 2) and the Start Network has struggled to find funding for its innovative approaches: ARC Replica and the Drought Financing Facility. ${ }^{124}$

The maximum payout from ARC is currently $\$ 30 \mathrm{~m}$, whereas the cost of responding to drought will clearly be much more than this. Haiti's maximum payout under CCRIF is $\$ 35 \mathrm{~m}$ for tropical cyclones and $\$ 20 \mathrm{~m}$ for earthquakes; the World Bank notes that radically increasing coverage (to $\$ 328 \mathrm{~m}$ and $\$ 150 \mathrm{~m}$ respectively) would be 'more adequate', but annual premiums would increase to $\$ 15 \mathrm{~m}$ and $\$ 3.5 \mathrm{~m}$ respectively, which is considered prohibitive. ${ }^{125}$

Insurance cannot therefore replace humanitarian aid, but it can be a complement.

Table 2: Comparison of humanitarian costs and insurance payouts

\begin{tabular}{|l|l|l|r|r|r|}
\hline Risk & Country & Disaster & $\begin{array}{l}\text { UN } \\
\text { Humanitarian } \\
\text { Appeal for } \\
\text { emergency } \\
\text { needs (\$m) }\end{array}$ & $\begin{array}{l}\text { Payout } \\
\text { amount } \\
\mathbf{( \$ m )}\end{array}$ & \multicolumn{2}{|l|}{$\begin{array}{l}\text { Payout as } \\
\text { percentage } \\
\text { of } \\
\text { humanitarian } \\
\text { needs }\end{array}$} \\
\hline ARC & Mauritania & Sahel drought, 2015 & 94.6 & 6.3 & $6.7 \%$ \\
\hline ARC & Niger & Sahel drought, 2015 & 375.5 & 3.5 & $0.93 \%$ \\
\hline ARC & Senegal & Sahel drought, 2015 & 59.5 & 16.5 & $28 \%$ \\
\hline ARC & Malawi & El Niño drought, 2015-16 & 366 & 8.1 & $2.2 \%$ \\
\hline CCRIF & Haiti & Earthquake, 2010 & 575 & 7.8 & $1.34 \%$ \\
\hline CCRIF & Haiti & Tropical Cyclone Matthew, & 139 & 23.4 & $16.8 \%$ \\
\hline PCRAFI & Tonga & Tropical Cyclone lan, 2014 & 13 & 1.9 & $9.8 \%$ \\
\hline PCRAFI & Vanuatu & Tropical Cyclone Pam, 2015 & 95 & 1.9 & $2 \%$ \\
\hline
\end{tabular}




\section{WHICH INSURANCE MODELS COULD DELIVER FOR POOR PEOPLE?}

Poor people are obviously highly vulnerable to shocks pushing them into destitution and loss - can insurance protect them from this?

\section{A MAJOR EVIDENCE GAP}

As already stated in this paper, there is a big gap in empirical evidence, which poses a challenge in understanding the impact of insurance on affected populations. This is partly because many schemes have been only pilots and have folded after a few years, and partly because proper monitoring and evaluation (M\&E) systems have not usually been used. Even where impact has been considered, there has been a tendency not to differentiate between different kinds of household on the basis of income or sex.

Commercial insurers would be expected to prioritize growth and profitability, and perhaps consider impact evaluation as a 'nice to have' feature rather than core business. ${ }^{126}$ They are even less likely to consider impacts on gender, equity, vulnerable groups and social cohesion; whether some people are excluded or informal risk-sharing systems are squeezed out; whether the scheme works for tenants, female-headed households or those who cannot prove land ownership; and whether there are negative unintended consequences.

While it may not be reasonable to expect insurers to have the skills to do this, it is not acceptable that donors and governments, which are investing millions of dollars of public money in these schemes, have not worked with them to develop robust standards for impact evaluation. Even now, for the IGP the primary goal of M\&E is 'tracking the number of poor and vulnerable people with insurance coverage in a transparent and accountable manner'. ${ }^{128}$ This is entirely about coverage, it says nothing about impact.

There is some good practice to learn from, but this needs to be standardized. For example, the R4 programme has an established framework that looks at four areas of measurement of resilience: processes of social change, resilience capacities, well-being and rights, and changing context. ${ }^{129}$

There is a real need to strengthen M\&E approaches to ensure that impact is better understood. And this requires investment. Oxfam has a commitment across all its programming that $5 \%$ of programme budgets will be spent on M\&E and learning, ${ }^{130}$ and this figure would be expected to be higher for innovative programmes. Establishing this norm within the IGP could help to ensure that IGP schemes achieve quality as well as quantity.

\section{MICRO-INSURANCE}

Many different products have been designed and offered in developing countries but, so far, all of those aimed at smallholder farmers have struggled to deliver an efficient solution at scale. Improving the product (supply, design, price), it is assumed, will transform latent 
demand into actual demand, thereby enabling scale-up and sustainability, but this has yet to be achieved. ${ }^{131}$

\section{NEED TO DEFINE A POVERTY THRESHOLD}

Most commentators would now agree that standalone micro-insurance is not the best option for the poorest people, as they have few assets to insure, many risks to cover and premium payments could push them further into destitution. ${ }^{132}$ However, there remains a lack of clarity on what 'poorest' actually means here. As one example, in Haiti, the World Bank estimates that only $3-5 \%$ of the population have a disposable income that is sufficient for them to be considered as potential micro-insurance clients. ${ }^{133}$

For subsistence farmers, who often produce barely enough food to consume, the combination of basis risk, high premium costs, low access to financial services and the fact that micro-insurance covers only one or two pre-defined hazards (e.g. drought, but not pests) means that not taking it up is a rational choice. ${ }^{134}$

However, micro-insurance could have an important role in preventing vulnerable people, those just above a certain income or asset threshold, from being pushed into extreme poverty due to shocks. ${ }^{135}$ An obvious question, then, is what is this critical threshold and how can the impact of insurance be maximized for the vulnerable? Yet surprisingly, this seems to be a question that is not often asked in the insurance debate, and more research is urgently required on this area.

Livestock is a productive asset, the loss of which can easily push people into a poverty trap from which it is incredibly difficult to escape. Insurance could have a valuable role to play in preventing this. Research from Kenya shows that the minimum viable herd size to support an average pastoralist household's consumption needs and to survive droughts is around 8-12 Tropical Livestock Units. ${ }^{136}$ Insurance could be specifically targeted for those just above this threshold.

In terms of agriculture, research commissioned by Oxfam suggests that micro-insurance is not suitable for subsistence farmers where: ${ }^{137}$

- crops are produced primarily for on-farm consumption, with little excess production for sale and low use of technology (own seed varieties, no purchased fertilizers or plant protection chemicals);

- there is very little cash investment, and the farmer bears no financial or credit exposure in relation to production;

- the premium cost exceeds $10-15 \%$ of the value of the assets insured. In this case, it is very unlikely that the returns from growing the crop and selling part of the harvest, after deducting for costs, will be adequate to cover the additional cost of insurance.

This work on thresholds is somewhat theoretical or country-specific - it needs further exploration and testing in other contexts, and for impacts on gender. Developing thresholds of this sort could act as a useful rule of thumb for future insurance schemes, enable appropriate targeting, and would help to avoid wasting scarce public resources.

\section{'But who will insure the 800 million people living in extreme poverty, on less than $\$ 1.90$ a day? Think of the farmer who was already struggling to survive before the water swallowed her small field. Are we asking her to afford insurance when her family is already going to bed hungry?'}

Winnie Byanyima, Executive Director, Oxfam International 
Poor people face a huge range of constraints that prevent them from flourishing economically; these constraints and vulnerabilities must be fully understood before knowing whether microinsurance is an appropriate solution and how it might best be applied.

For example, farmers face weather risks which could potentially be reduced with insurance, but they also face other constraints such as lack of timely access to quality seeds and fertilizers, poor rural transport, low market prices, and so on, which insurance will obviously not address. While the Indian government has invested in insurance for many years, farmers there face structural inequalities which mean that it is unlikely to be successful without additional measures (see Box 8).

One key problem for farmers is access to credit, and there is an assumption that insurance can help to unlock this, but a recent review finds an evidence gap. ${ }^{138}$ Analysis for Oxfam in Burkina Faso found that a major constraint for maize farmers was indeed lack of access to credit, but that lenders were unlikely to extend credit, even for farmers who had insurance, because poorly developed supply chains for cereals mean that farmers may not have the necessary opportunities to achieve productivity gains and a margin to cover the repayment. ${ }^{139}$

For poor people, the optimum solution is likely to be an integrated combination of approaches ${ }^{141}$ - such as the R4 programme (Box 6) and USAID's Nataal Mbay programme in Senegal. ${ }^{142}$

\section{Box 6: Insurance and the R4 programme}

The R4 Rural Resilience Initiative is a partnership between the World Food Programme (WFP) and Oxfam America which aims to support food-insecure communities facing increasing frequency and intensity of climate disasters and other shocks. The programme integrates four risk management strategies: improved management of natural resources and diversification of livelihoods (risk reduction), weather index insurance (risk transfer), micro-credit (prudent risk taking) and savings (risk reserves). R4 is currently operational in Ethiopia, Malawi, Senegal, Zambia, Kenya and Zimbabwe. Through its innovative integrated risk management approach, $\mathrm{R} 4$ enables the poorest farmers to access crop insurance by participating in risk reduction activities.

R4 has been running for longest in Ethiopia, where it is linked with the national safety net programme. A recent evaluation ${ }^{143}$ found that it is helping smallholder households, especially female-headed ones, to reduce the impact of drought on food security while maintaining their productive assets. Evidence of improvement in agricultural production in good years is limited, but declines in food security were reduced during a severe drought in 2015. R4 supports food security while enabling farmers to maintain and accumulate livestock, which is the most important productive asset among smallholder farmers in Tigray. The integrated approach of the R4 programme seems to enhance the variety of coping strategies at the disposal of households.

In Senegal, the R4 programme has demonstrated strong results in reducing the adverse impact of shocks on food security and non-food expenditure. Households with insurance spent more on average on agriculture inputs than those without insurance. It seems likely that, protected by insurance, farmers felt more confident in investing in agricultural inputs. Staple crop production has increased and the programme has also strengthened social bonds and women's empowerment. ${ }^{144}$ 
It should be noted that these results come from the integration of different elements of the programme: it is not possible to clearly quantify the impact of the insurance element alone. Some questions remain in relation to the insurance aspect, such as whether farmers have adequate risk protection in the event of a serious drought; how to further reduce basis risk, increase coverage, and find sustainable solutions. It is also not known whether greater benefits could be achieved through other options, such as promoting higher levels of savings, greater support for climate-resilient agriculture or increased social protection.

The next phase of R4 in Ethiopia will work to achieve substantial scale: it will focus on the graduation of farmers to pay fully in cash, build a strong culture of savings, reach out further to market-ready farmers and work to create an enabling policy and infrastructure framework.

\section{MACRO- AND MESO-INSURANCE}

Macro and meso schemes seem to offer quite a bit of potential for meeting the needs of poor people. It is interesting that a review of Kenya's Financial Sector Deepening programme recommended scaling down commercial micro pilots and concentrating on meso- and macro-level cover instead. ${ }^{145}$

\section{MACRO-INSURANCE}

A macro-insurance scheme should pay out quickly to the disaster-affected government, so the challenge is to ensure that this funding reaches affected households quickly.

Some schemes - such as CCRIF and PCRAFI - are not specifically designed around meeting the needs of poor people; rather, their objective is to provide financial liquidity to the government to support a faster response. A fast response is of course likely to support poor people, but this cannot be confirmed or optimized as there is no requirement to spend payouts on specific things and no formal monitoring or reporting of their use. From what we do know, payouts have been used to pay civil servants' salaries (Haiti); ${ }^{147}$ to restore power grids, water systems and other basic services (St Lucia, Dominica and St Vincent and the Grenadines); ${ }^{148}$ and to transport goods and emergency personnel to islands (Tonga and Vanuatu). ${ }^{149}$

By contrast, ARC has invested heavily in supporting governments to develop contingency plans, which are verified by external experts, to try and ensure a swift and appropriate use of the payout. So far, this has not been very successful - only in one case (Mauritania) out of four has it really worked, with a range of bureaucratic and programmatic delays in Niger and Senegal, and basis risk in Malawi causing a nine-month delay. ${ }^{150}$ These problems could potentially be ironed out, but they will require major investment, particularly in capacity building.

In Mexico, CADENA - the national insurance scheme for poor farmers - has been successful for the 'moderate poor', but not the 'extreme poor' (Box 7).

To successfully meet the needs of poor people, macro-insurance needs to invest considerably more in effective contingency planning, delivery systems, and targeting. One attractive option in principle is to channel payouts through scalable social protection 
systems; this could provide a quick way of getting payments to vulnerable people. Unfortunately, there is still a major gap in social protection systems, and significantly more investment is required (section 5).

\section{Box 7: The CADENA national insurance scheme for small farmers in Mexico}

In 2003 Mexico was the first country to use macro-level agricultural index insurance products to finance a national social safety net programme for small-scale farmers and livestock producers, for whom commercial crop insurance is not necessarily an appropriate or cost-effective mechanism, and to replace traditional ad hoc postdisaster relief schemes.

The CADENA programme is wholly funded by government - approximately $90 \%$ from the federal government and $10 \%$ from state governments. It is provided free to farmers across the country below a certain size of holding: less than 20 hectares of rain-fed crops and up to 30 livestock units. The insurance payout is received by the state government, which then distributes it to farmers.

This is a large programme that has been running for several years, and there have been several evaluations. Headlines from these are:

- Costs: 'While the cost of insurance appears to be high relative to the payouts, the benefits exceed the costs for a substantial range of outcomes.'151

- Benefits: insured farmers have cultivated a larger land area in the season following a weather shock, and have higher household expenditures per capita, indicating welfare gains, although some of the benefits may be offset by a reduction in remittances from abroad. ${ }^{152}$

- Who benefits: the scheme benefits those in moderate poverty, but not those in extreme poverty. ${ }^{153}$ It is not known whether this is because the extreme poor are not eligible because they do not own land, or whether targeting is ineffective. ${ }^{154}$

- Improvements required: speeding up the delivery of funding to farmers - some cases have taken over six months - and keeping eligibility criteria under constant review, to ensure that it is the vulnerable poor who are benefiting. ${ }^{155}$

\section{MESO-INSURANCE}

Meso-insurance is where a 'risk aggregator', such as a microfinance institution, farmers' cooperative or community-based organization pays the premiums and receives the payout. In one model, the risk aggregator takes out the insurance to protect its loan portfolio, and keeps the payout in the event that households or farmers default on their loans. In this case, the benefit to poor people is indirect, through the ability of the aggregator to continue to operate and reschedule loans. In another model, the risk aggregator distributes the payout directly to the member households.

Meso-insurance schemes seem to have many advantages, the key ones being that they already have strong links with communities and proven distribution networks and therefore they can easily achieve scale. Targeting, of course, will rely on membership or be limited to those who have loans, and may exclude some people, including potentially the poorest.

However, meso-insurance is still very new and there is no empirical evidence to work from. Emerging schemes should be carefully monitored for their impact on poverty and social equity. Promising schemes include ARDIS (African and Asian Resilience in Disaster Insurance Scheme), a major new initiative launched by VisionFund to provide insurance for microfinance institutions to enable lending to poor people post-disaster, ${ }^{157}$ and Oxfam's 
Bangladesh Flood Index Insurance Programme, which is providing business interruption coverage for very poor wage labourers.

\section{PRO-POOR BUSINESS MODELS}

To date, the search for successful insurance has focused almost exclusively on the commercial/shareholder model. Private sector actors certainly have major expertise in risk and financial analysis, but the approach is market- and consumer-based, with profit as a driver. Takaful is a rapidly growing Islamic alternative to commercial insurance; there are a variety of different models, all of which have shareholders, but vary in terms of where any profits go. ${ }^{158}$

In a shareholder model, there is a concern that profits to shareholders could be maximized by either high premiums or low payouts, which clearly does not bode well for people living in or near poverty. A further problem is that some insurance companies profit from climate change through their investments in fossil fuel companies and other high-emission sectors.

\section{MUTUALS AND COOPERATIVES}

Mutuals and cooperatives offer a viable alternative to the shareholder model. Mutuals do not work for profit or pay dividends to shareholders, and thus are usually able to offer lower premiums. Mutuals can operate at sovereign level (CCRIF and ARC are mutuals) but their real value-added is at community level, where there is huge potential to provide services that genuinely meet the needs of poor people. There is a broad variation in the size and scope of such organizations, but their roots are at community level and they embrace values of equity, solidarity, empowerment and social capital. Their proximity to members and shared ownership facilitate claims settlement and self-regulation on fraud.

Importantly, their community links mean that mutual insurance providers are well placed to provide support and assistance on risk reduction, adaptation and climate-resilient agriculture. For example, before The Goat Trust in India offers insurance, it will undertake a baseline study on goat mortality and an aggressive risk reduction programme - involving measures such as immunization, primary medical care and livestock nutrition. These measures have brought animal mortality rates down from as high as $28 \%$ to under $5 \% .{ }^{159}$

There are real advantages therefore to providing financial services for poor people via mutuals and cooperatives. However, mutuals also suffer from some key constraints which will require explicit and targeted support, as outlined below:

- Mutuals work well for idiosyncratic risk (i.e. risks that affect individuals such as death or illness) but most mutuals cannot access reinsurance due to regulatory requirements. This means that they are vulnerable to catastrophic risk, where everyone in the community is affected, which could potentially cause the scheme to collapse. However, there are solutions to this: in Mexico, the government insurer Agroasemex provides reinsurance for the national network of mutuals, Fondos; ${ }^{161}$ in Bangladesh, the Palli Karma-Sahayak Foundation (PKSF) established a Covariant Risk Fund with donor support; ${ }^{162}$ and the International Cooperative and Mutual Insurance Federation (ICMIF) links major cooperatives in developed countries with smaller ones in developing countries to provide informal reinsurance. ${ }^{163}$

- Many mutuals are small, whereas successful insurance requires scale in order to pool risk and cover operational costs. Financial and technical support will be required to 
achieve federation at scale. One successful example is the PKSF cattle credit mortality insurance scheme, which targeted 28 microfinance institutions across Bangladesh, thereby offering the spread of risk and potential for growth. ${ }^{164}$

- Mutuals often operate with benign neglect from regulators. This needs to change, in order to develop a regime that can balance the solvency requirements of risk carriers with the risks of covering the lives and livelihoods of poor people. ${ }^{165}$

\section{THE MISSING “P” IN PPPPS}

Public-private partnerships (PPP) are the most common model being used for insurance in developing countries. The stated advantage of PPPs is that they can combine the different skills and resources of the partners in innovative ways, such that governments can focus on policy, planning and regulation while the insurance industry can provide technical and management capabilities. ${ }^{166}$

However, what is missing here is a focus on communities. Current guidance on PPPs for insurance does not stress the importance of actually engaging with affected people in the design and development of such schemes. ${ }^{167}$

There are many positive examples of participation with communities to develop specific schemes; this is certainly Oxfam's experience ${ }^{168}$ and it can be seen at national level too. For example, reform to the Catastrophes Naturelles insurance system in France was based on a wide consultation process with all stakeholders - disaster-affected communities, consumers, local authorities, companies, the insurance market, the construction market, scientific organizations - to develop a shared vision and to strengthen the reform process. ${ }^{169}$

However, there are also cases where this has not happened. For example, after a few years of operation, the evaluation of CCRIF sought feedback on the facility's impact from the standpoint of governments and various institutions, but not from the population affected by catastrophic events, ${ }^{170}$ and the ARC evaluation found 'strong evidence to suggest that civil society and NGOs have often not meaningfully been involved'. ${ }^{171}$

A shift is needed to PPPPs: public-private-people partnerships, to rebalance the roles and interests of all parties to achieve effective outcomes.

'Traditional approaches to decision-making were born to the colonial and immediate postemancipation era; it typically involved a top down approach with little engagement with Civil Society... Civil Society participation in national decisionmaking is increasingly recognized as effective means of addressing development challenges including management of natural resources, economic development and social equality.'

InterAmerican Development Bank $^{172}$ 


\section{KEY BUILDING BLOCKS FOR RESILIENCE}

The evidence around the impact and cost-effectiveness of insurance for poor and vulnerable people remains incomplete. So what does work? And how can CDRF solutions support this?

\section{SOCIAL PROTECTION}

The past two decades have seen a rapid expansion of social protection programmes in the developing world, targeting poor and vulnerable people, and with growing government ownership. Social protection is a right for all ${ }^{174}$ and is explicitly transformational in that it addresses social equity and exclusion.

There is growing support for the concept of the Social Protection Floor (SPF), which 'should ensure, as a minimum that, over the life cycle, all in need have access to essential health care and to basic income security which together secure effective access to goods and services defined as necessary at the national level. ${ }^{175}$ According to 2015 guidelines, social protection should also 'protect populations at increased risks of climate-related hardship,' mostly through cash transfers or employment schemes. ${ }^{176}$ An important principle behind the SPF is its universal approach, with a central role for governments, and financed through both contributory and tax-based mechanisms.

\section{EFFECTIVE AND COST-EFFECTIVE}

Social protection initiatives have been accompanied by robust evidence-building research which has demonstrated their positive impact on poverty alleviation and the well-being and livelihoods of poor people. ${ }^{177}$ A growing body of evidence finds that social safety nets - one element of social protection, comprising non-contributory transfers in cash or in kind to individuals or households in need - are an efficient tool to support poor people through shocks, and this is even more pronounced when they are integrated into social protection systems. ${ }^{178}$

- Safety nets are effective: a recent meta-evaluation covering 27 safety net programmes in 14 African countries found strong evidence of increases in food and other consumption and in livestock and productive assets, as well as incomes and earnings. ${ }^{179}$

- Safety nets offer value for money: the annual cost of Ethiopia's Productive Safety Net Programme is equivalent to $1.2 \%$ of GDP, while safety net coverage in Kenya is equivalent to $0.8 \%$ of GDP. ${ }^{180}$ Safety nets are often thought to be expensive, but studies and simulations have shown otherwise: the cost of not protecting the poor from the effects of shocks can result in even more costly setbacks in terms of long-term development.

Unfortunately, there are still many gaps: in many countries, social programmes cover less than half of the poorest quintile ${ }^{181}$ or are targeted only at particular categories of recipients, such as the elderly.

From the perspective of equity and cost-effectiveness, it is imperative to invest in and expand social protection systems that can be adapted or scaled up (and down) in response 
to shocks. Successful shock-responsive protection systems remain rare, but there have been experiences now in Kenya, Ethiopia, Uganda, the Philippines, Tanzania and Lesotho, with new schemes being developed in the Sahel, and much effort is being made to learn from and expand this work. ${ }^{182}$

Financing scalable social protection remains a challenge, and CDRF measures could be key in supporting scale-up in relatively major crises (not annual hunger gaps). In fact, seven African countries (Ethiopia, Kenya, Lesotho, Mali, Mauritania, Niger and Uganda) have asked for technical support from the World Bank in developing financial risk management approaches to help build shock-responsive social protection systems; ${ }^{183}$ Uganda has now arranged contingent credit to fund its scale-up. Insurance could provide the funds to scale up social protection programmes in times of crisis; this is precisely what Mali would do if it received an ARC payout. ${ }^{184}$

\section{RISK REDUCTION AND ADAPTATION}

A huge effort is required to address the growing impacts of disasters and climate change. This obviously needs to start with mitigating the impacts of climate change. Yet the world is already locked in to substantial climate change from previous emissions, so it is imperative for societies to adapt to a changing climate, to reduce the risks that poor communities and countries face from future hazards and to provide support for those affected by disaster loss and damage.

A radical increase is required in actions taken to help communities and ecosystems cope with a changing climate and to identify, assess and reduce the risks of disaster. Adaptation and risk reduction are proven to be both effective and cost-effective. One analysis of DRR programmes found that 102 out of 117 were cost-effective, with higher impacts for those in less developed countries. ${ }^{185}$ Some measures are strikingly so: for example, early warning systems in developing countries could yield benefits 4 to 36 times greater than the cost. ${ }^{186}$ Yet DRR remains critically underfunded.

There is a huge and growing funding gap. Disaster response is prioritized over risk reduction and only 40 cents in every $\$ 100$ of development assistance is spent on DRR. ${ }^{188}$ In terms of adaptation funding, the estimated needs are between $\$ 140 \mathrm{bn}$ and $\$ 300 \mathrm{bn}$ per year by $2025 / 30 ; 189$ this compares with around $\$ 9$ bn per year that is actually provided by developed countries. ${ }^{190}$ (These are figures for 2013/14; Oxfam will soon publish estimates for 2015/16 which suggest that adaptation finance has only increased a little).

This is an enormous challenge, and one that is a priority. It certainly means that CDRF and insurance should not disincentivize or crowd out funds - or indeed, scarce human resources and institutional capacity in developing countries - from adaptation and resilience-building options that are proven to deliver value for money. Our rapidly-warming world requires a focus on proven solutions.
'To achieve scale, agricultural insurance needs to be part of a holistic approach for agricultural development with basic services in place such as access to inputs, access to data and access to delivery channels in addition to a strong collaboration between insurers, farmers and governments.'

Francesco Rispoli, IFAD, Italy $^{187}$ 
If risk reduction and adaptation options are assessed by looking only at their impact on reducing asset losses, this will produce skewed results: it will favour initiatives that protect or support richer areas or people, simply because they have more assets. ${ }^{191}$ While the loss of poor people's assets may have a low economic value in absolute terms, it can nonetheless represent an existential loss for them. Losing two goats might be inconsequential for a commercial farmer, but it could threaten the livelihood of a poor farmer.

As the IGP's objective is to create policies and programmes to support poor and vulnerable people, the cost of assets cannot be the key metric. The World Bank proposes a well-being measure, which models the effect of asset loss on consumption and income, so that, for example in Guatemala, a $\$ 1$ loss in pure asset terms represents a $\$ 4$ loss when considering the impact of that loss on the resilience of poor people.

This approach radically changes the landscape of which programmes have the most impact and which to support. Solutions are country-specific, but the top three priority measures from a well-being perspective across 55 developing countries are: ${ }^{193}$

- Firstly, reducing the hazard exposure of poor people - this would include, for example, upgrading slums with improved drainage;

- Secondly, providing universal access to early warning systems;

- Thirdly, accelerating reconstruction. ${ }^{194}$

The same research does not even consider market insurance for the poorest $20 \%$ of the population as a viable option; insurance for the other $80 \%$ is only a priority measure in 4 out of 55 developing countries. ${ }^{195}$

Policy measures also need to be considered for their impact on gender. Too often, policies and budgets that appear gender-neutral on the surface in reality further increase inequality and contribute to the ongoing subjugation of women. Gender impact analysis is crucial to determine how different groups will be affected differently by the same policy. For example, analysis by Oxfam in five countries finds that women are being failed by governments and donors, whose agricultural investments (resources and technical assistance) are not reaching women farmers. ${ }^{196}$

\section{Box 8: Smallholder agricultural insurance in India}

The smallholder farmer sector in India is in crisis; the most extreme indicator of this being the huge number of farmer suicides, the majority of which are due to bankruptcy, indebtedness and issues related directly to farming. ${ }^{198}$

The Indian government has undertaken a range of reforms, including farm debt waivers, and has invested massively in insurance, so much so that the country now has the best-established and most dynamic agricultural micro-insurance programme in the world. The new PMFBY scheme (Pradhan Mantri Fasal Bima Yojana - literally, 'Prime Minister's Crop Insurance Scheme') was introduced with the following promise: 'The scheme will be a protection shield against instances of farmer suicides because of crop failures or damage because of nature.'199

However, on its own, the scheme is unlikely to achieve this goal. What it can do is allow vulnerable small-scale farmers access to credit and ensure that they remain creditworthy in the event of crop failure. But what is needed is a comprehensive approach that addresses all of the factors that make farmers vulnerable.

'What matters is
not only how
much benefit a
project
generates, but
also who
benefits.'

World Bank, Unbreakable report (2017) ${ }^{192}$

\section{'A robust irrigation network, ample rural/farm related infrastructure, crop diversification, multi-cropping, assured, but reasonable minimum support price, guaranteed purchase and fair value to the farmer for his produce. All these need to be taken care of first. Then comes the crop insurance. But agriculture insurance cannot run with profit motive. Crop insurance is the last resort. Not the first option."}

Chandra Bhushan, Deputy Director General of CSE, an Indian independent think $\operatorname{tank}^{197}$ 
One major problem is the increase in production costs, which the government's Minimum Support Price (MSP) ${ }^{200}$ barely covers; for example for sugar cane the MSP is INR 1,000-1,100, against a production cost of INR $900-1,000$ per unit. When interest on loans is included, the MSP cannot protect farmers' tiny profit margins from shrivelling into debt. ${ }^{201}$

Other issues include the need for rural social banking, the loss of subsidies for fertilizers and seeds and the lack of irrigation facilities in arid regions; these have increasingly pushed farmers to rely on informal sources of credit at exorbitant rates, leading to debt, landlessness and the entrenchment of inequalities in gender, caste and class. ${ }^{202}$

Insurance might be one part of the solution, but only when it is part of a comprehensive risk management approach that addresses the many reasons for farmers' vulnerability.

\section{A COMMUNITY-CENTRED APPROACH}

To support social justice and build transformative resilience, a bottom-up and communitycentred model is required. This is not an easy option, but there are no simple solutions. It also flies in the face of much donor support, which tends to favour projects at scale.

Cooperative and community-based organizations operate much closer to communities and are able to draw on local context and knowledge, while being driven by an understanding of community needs, aspirations and capacities. They can provide a range of services to poor people - training on climate-smart agriculture, capacity building for business, finance and livelihoods options, savings, loans, insurance, and so on. Importantly, they are often particularly effective at empowering women, building their agency and voice and realizing their potential within households and communities, which is crucial for transformative resilience.

Such groups offer much potential (Box 9) and need to be part of the solution to provide more transformational change. Federation - joining up community-based organizations into a single group with centralized support - can provide economies of scale for services and products, but governance can be a challenge, and a careful balance must be struck to ensure that federation does not lead to a loss of community focus and ownership. ${ }^{203}$

\section{Box 9: Self-help groups and Oxfam's Saving for Change programme}

Savings groups, self-help groups and similar community-based programmes have demonstrated real benefits. Studies find that savings groups do include very poor people ${ }^{204}$ and provide access to financial lump sums that could not be realized otherwise. ${ }^{205}$ There is little evidence, however, that they reduce hazard risk. ${ }^{206}$

Oxfam's Saving for Change ( $\mathrm{SfC}$ ) programme provides basic financial services to more than 730,000 women across seven countries via small savings groups. The programme trains groups of poor women ( $82 \%$ of whom live on less than $\$ 1.25$ a day) to save regularly, borrow from their group's fund when necessary and repay loans with interest. The impacts are clear: members invest more in livestock, the food security gap closes, and social cohesion and women's confidence are built.

As the groups have become established, women have requested more training, services and products adapted to their needs. Groups now serve as a platform for delivering additional capacity-building activities in business, agriculture, citizenship, mobile banking and also basic advocacy skills: SfC is as much about strengthening members' voices as it is about increasing financial inclusion.

'We are absolutely amazed at what the self-help groups have achieved. It is remarkable to see how these women's groups are able to manage their fastexpanding role in the area's economy, while demanding, and receiving, better services from local governments to strengthen their functioning. It is beyond what we can define in the World Bank as women's empowerment.'

Junaid Ahmad, World Bank Country Director in India 207 
A forthcoming paper from Practical Action outlines how to develop an integrated national resilience finance system which could include member-run institutions of the poor, such as federated self-help groups, village savings and loans associations and cooperatives, engaging with decentralized state structures, supported through locally managed funds and an integrated, shock-responsive national social protection system, with resourcing gaps met by rights-based international financing. ${ }^{208}$

\section{WHO PAYS?}

DRR, climate change adaptation and social protection schemes remain massively underfunded; further, the gap between humanitarian needs and funding is growing. Providing funding for CDRF schemes will further strain limited budgets. More resources are required.

One report finds that 'plausible development' of insurance schemes in low- and middleincome countries could reduce losses by $\$ 4.4$ bn per year by $2030 .{ }^{210}$ But this is not free money. The report says nothing about the premiums required to achieve that coverage, or who will pay.

From a perspective of international climate justice, poor countries should not have to bear the burden of worsening climate risks that they have done little to create. Under the UNFCCC, developed countries accept an obligation to provide financial assistance to developing countries for both mitigation and adaptation. This is further supported by the UNFCCC principle of Common but Differentiated Responsibilities and Respective Capabilities, which means that countries that have benefited from carbon emissions and have grown rich along the way bear a responsibility to support others - through sustained, predictable and long-term financial assistance.

However, rich countries are dragging their feet. In 2009 they promised to increase their financial support to $\$ 100 \mathrm{bn}$ a year by 2020 , but projections indicate that only a fifth of that amount may come in the form of public finance for adaptation, ${ }^{211}$ and the promise does not include financial support to deal with future losses and damages from climate change.

CDRF will have a role to play in ensuring that poor and vulnerable countries can better manage the financial implications of future disasters, especially as climate change impacts are set to worsen and costs are becoming (more) unaffordable. Yet CDRF should not be used as a way of shifting the increasing cost of climate chaos onto poor countries, for example by forcing them to pay insurance premiums. ${ }^{212}$ This could be perceived as developed countries offloading humanitarian responsibilities for disasters that have been exacerbated by climate damages they have caused themselves.

If the evidence base improves, insurance, as one part of an integrated and comprehensive package of measures to support poor people, could play a beneficial role - but the associated costs should be shouldered by those who have intensified the risk.

To meet these needs, new and innovative sources of funding need to be explored to generate such funding at scale, such as financial transaction taxes (FTTs), revenues from carbon pricing systems (e.g. for international air and sea transport) or levies on fossil fuel extraction, ensuring that developing countries are not burdened by such levies.

'We understand
that climate
change
potentially poses
a serious financial
threat to society
as a whole, with
implications for
the insurance
industry in areas
such as
catastrophe risk
perception,
pricing and
modeling
assumptions.'
AlG's 2017 Annual
Report ${ }^{29}$




\section{CONCLUSIONS AND RECOMMENDATIONS}

In the light of the increasing impact of disasters resulting from natural hazards, the objective of CDRF to provide better financial management of risks is clearly a good one. However, it must be pursued with the imperative to protect people in poverty and must be implemented in combination with additional components of a comprehensive agenda around adaptation and resilience. And crucially, the political decisions made - how much protection to provide, and to whom - should be open to public scrutiny and made after meaningful engagement with civil society.

Insurance is not a quick fix to deal with inadequate financial support provided for development, adaptation and humanitarian needs. Insurance will not be appropriate for all disasters, it is inherently expensive, and the current evidence gap must be overcome. At this early stage, it could well be argued that it is too early to be striving to achieve a target on quantity (getting insurance to 400 million more poor and vulnerable people) without an equally clear focus on quality.

From a narrow focus on market solutions, insurance seems to offer a logical option. But this should not be the only entry point. Standalone commercial insurance is not an automatic fit for development. To develop effective approaches, it will be vital to remember that:

- It is not a tool for dealing with structural inequalities; very few schemes even consider social equity or gender concerns.

- Most current models are not well adapted to reducing risk or supporting adaptation; the 'no betterment' principle of indemnity insurance undermines the need to build back better.

- Significant subsidies will need to be provided and further cost-benefit analysis is needed to demonstrate the pertinence of such investments and the most appropriate target for subsidies.

- The incidence of basis risk throw into sharp relief the difference between an actuarial perspective, which resists ex gratia payments as they are deemed to undermine the whole insurance model, and a humanitarian perspective which considers people's needs.

These limitations could potentially be overcome, but first they need to be clearly understood. A pro-poor and pro-equity approach to insurance is not as simple as who pays the premiums or the size of the subsidy. Pro-poor solutions must be found, including adding in the missing ' $p$ ' - public-private-people partnerships - and supporting mutuals and cooperatives.

Standalone microinsurance seems not to be appropriate for the poorest people, who have many risks, little income and few assets to insure. It may be a solution to prevent vulnerable people falling into poverty, but more work is needed to identify the poverty or asset threshold for success. Understanding the root causes of vulnerability must be the starting point; micro-insurance may only deliver when combined with other measures such as access to credit, inputs and markets.

Macro- and meso-insurance models do seem to offer potential, especially if they are integrated into comprehensive programmes to increase resilience. But much more 
investment is required to develop effective contingency plans, delivery mechanisms and targeting to ensure that payouts swiftly reach poor people.

And of course, CDRF and insurance are means to an end, not ends in themselves. Some $\$ 715 \mathrm{~m}$ has been committed to InsuResilience work in less than three years, the vast majority of which is for insurance rather than for research or other CDRF mechanisms. ${ }^{214}$ So while recognizing that innovative approaches will be needed, it is a legitimate question to ask where limited public resources are best channelled. Is enthusiasm for insurance, including the InsuResilience target, skewing efforts and diverting investment from betterestablished and proven interventions that would probably make a better job of reducing the risks faced by the world's poorest people? The urgency of our warming world suggests the focus should be on proven interventions.

\section{RECOMMENDATIONS}

\section{Donors and governments should ensure that protection is provided for the poorest people}

- Ensure that social protection and safety nets are available to protect the poorest people, funded by progressive taxation and international aid. CDRF measures could play a role in funding shock-responsive systems.

- Prioritize risk reduction and adaptation to reduce the risks that poor people face. Public investment in CDRF should not disincentivize or otherwise crowd out investment in risk reduction or adaptation. Use the World Bank's well-being metric, or similar, to identify an appropriate package of measures that delivers for poor people. ${ }^{215}$

\section{IGP partners should identify the right balance of CDRF priorities}

- Ensure that the target to reach 400 million people with insurance does not skew programme responses. The IGP should provide a) impartial technical advice on and b) funding for the full range of CDRF and risk reduction tools, not just insurance, considering forecast-based financing, contingent credit and grants, resilience bonds, and so on.

- Develop pro-poor principles that will guide the work of the IGP, derived from the recommendations in this paper.

- Ensure that supported CDRF schemes are pro-poor and reduce risk: embedded within a strong and comprehensive risk management framework; explicitly seeking to incentivize and enable risk management and avoid maladaptation; and have clear contingency plans, delivery mechanisms and targeting protocols.

\section{All stakeholders should ensure that CDRF and insurance schemes are demand-led}

- Provide much clearer objectives, success criteria and indicators on reducing the vulnerability of affected populations.

- Foster schemes that are nationally and locally driven, both by government and affected communities. Support full participation of affected communities and capacity building and financial support for Southern CSOs.

- Provide support for the delivery of insurance through cooperatives, mutuals and selfhelp groups, including appropriate regulation and support for federation and reinsurance. 
- Support public-private-people partnerships - balancing the roles and interests of all parties to achieve effective outcomes.

- Ensure accountability and transparency. Support stronger national regulatory and parliamentary oversight, and the IGP should set up an independent facility where concerns can be registered and complaints investigated.

\section{Where insurance is being considered, all stakeholders should consider the} root causes of vulnerability and inequalities

- Analyse the root causes of vulnerability that drive risk, including structural inequalities affecting women and girls, older people, people with disabilities and marginalized and vulnerable groups.

- Prioritize options which achieve a more balanced distribution of risk across society, and ensure that measures to address power and structural inequalities are incorporated or provided alongside insurance.

- Commit to improving gender equity through the development of a gender framework, using disaggregated data, gender-sensitive design and further research to increase impact and avoid unintended consequences that may deepen existing inequalities.

\section{The IGP should support learning and increase programme quality}

- Build evidence, undertake research and focus on learning to stimulate an informed and nuanced debate and improve programme quality. The research agenda should include work to identify those for whom insurance is an effective and cost-effective option (and for whom it is not), more work on opportunity cost and alternatives and development of insurance schemes that support adaptive capacities.

- Radically increase funding and strengthen monitoring and evaluation. Rather than focusing primarily on counting coverage (to achieve the 400 million target), M\&E should focus on developmental impact, including social and ecological consequences, both intended and unintended, and any maladaptation. A minimum of $5 \%$ of programme spend should be invested in M\&E.

- Develop tools for the sector. The IGP should develop and/or promote minimum programme standards, an M\&E framework, a gender analysis tool and other tools to ensure impact as well as sustainability.

\section{All donors should support climate justice}

- In line with UNFCCC obligations, donors should provide sustained, predictable and long-term financial support for comprehensive disaster risk management and climate change adaptation, which may include CDRF.

- Develop alternative sources of finance for CDRF measures that address loss and damage, such as levies on fossil fuel extraction or revenues from carbon pricing systems.

- Request evidence from insurance company partners that they do not drive climate change through other investments in fossil fuels and other high-emission sectors or, at the very least, that there is a time-bound plan to phase out such investments as soon as possible. 
1 S. Hallegatte et al. (2017). Unbreakable: Building the Resilience of the Poor in the Face of Natural Disasters. World Bank Group, Climate Change and Development Series. https://openknowledge.worldbank.org/handle/10986/25335

2 At least $\$ 580 \mathrm{~m}$, maybe more: $\$ 550 \mathrm{~m}$ up to the end of 2016 for the InsuResilience target - this was purely for insurance; $£ 30 \mathrm{~m}(\$ 39 \mathrm{~m})$ from the UK, announced in July 2017 for the Centre for Global Disaster Protection, of which $£ 8 \mathrm{~m}(\$ 10 \mathrm{~m})$ was for insurance premium financing; $€ 110 \mathrm{~m}(\$ 125 \mathrm{~m})$ announced by Germany in November 2017 for the IGP. It is not clear how this splits out, but at least $€ 20 \mathrm{~m}$ was intended for World Bank technical assistance and $€ 15$ for the InsuResilience Solutions Fund.

3 Access to Insurance Initiative (2017). Scaling Up Agricultural Index Insurance in Africa: Building disaster resilience of smallholder farmers. 10th Consultative Forum. https://a2ii.org/sites/default/files/reports/10th_consultative_forum_briefing_note_final.pdf

4 See for example the Climatewise compendium: https://www.cisl.cam.ac.uk/business-action/sustainablefinance/climatewise/pdfs/climatewise-compendium-of-disaster-risk-transfer.xlsm/view

5 J. Hansen et al. (2018). Climate risk management and rural poverty reduction. Agricultural Systems https://www.sciencedirect.com/science/article/pii/S0308521X17307230?via=ihub. https://doi.org/10.1016/j.agsy.2018.01.019

6 L. Ralston et al. (2017). The Impacts of Safety Nets in Africa: What Are We Learning? World Bank Policy Research Working Paper 8255 http://documents.worldbank.org/curated/en/436571511364314467/pdf/WPS8255.pdf

7 D. Hugenbusch and T. Neumann (2016). Cost-Benefit analysis of disaster risk reduction: A synthesis for informed decision making. https://www.aktion-deutschland-hilft.de/fileadmin/fm-dam/pdf/publikationen/aktiondeutschland-hilft-studie-zur-katastrophenvorsorge-englische-version-english-version.pdf

8 K. Wethli (2014). Benefit-Cost Analysis for Risk Management: Summary of Selected Examples. World Bank. http://siteresources.worldbank.org/EXTNWDR2013/Resources/8258024-1352909193861/8936935$1356011448215 / 8986901$ 1380568255405/WDR15_bp_BenefitCost_Analysis_for_Risk_Management_Wethli.pdf

9 G. Stargardter (2017). Cuts hurt Mexico quake response, outlook ahead of 2018 vote. Reuters, 28 September 2017. https://www.reuters.com/article/mexico-quake-politics/cuts-hurt-mexico-quake-response-outlook-aheadof-2018-vote-idUSL2N1M600S

10 Personal communication with insurance expert practitioners, March/April 2018.

11 C. Averill and A. Marriott (2013). Universal health coverage: Why health insurance schemes are leaving the poor behind. Oxfam International. https://www.oxfam.org/sites/www.oxfam.org/files/bp176-universal-healthcoverage-091013-en_.pdf

12 D. Hillier and G.E. Castillo (2013). No Accident: Resilience and the inequality of risk. Oxfam International. https://policy-practice.oxfam.org.uk/publications/no-accident-resilience-and-the-inequality-of-risk-292353

13 A progressive tax is one that takes a larger percentage from high-income earners than it does from lowincome individuals.

14 S. Hallegatte et al. (2017). Unbreakable: Building the Resilience of the Poor in the Face of Natural Disasters. Op. cit.

15 D. Collins et al. (2009). Portfolios of the Poor: How the world's poor live on $\$ 2$ a day. http://www.portfoliosofthepoor.com/index.asp

16 Overseas Development Institute (ODI) event: 'Building back better': a resilient Caribbean. 30 January 2018. London. https://www.odi.org/events/4525-building-back-better-resilient-caribbean

17 S. Hallegatte et al. (2017). Unbreakable: Building the Resilience of the Poor in the Face of Natural Disasters. Op. cit.

18 UNISDR (2015). Ten-year review finds $87 \%$ of disasters climate-related. United Nations Office for Disaster Risk Reduction, 6 March 2015. https://www.unisdr.org/archive/42862

19 FAO (2018). 2017: The impact of disasters and crises on agriculture and food security. http://www.fao.org/3//8656EN/i8656en.pdf

20 ODI/RMS (2017). Mapping the Role of Insurance in Managing Disaster Losses: A study of low and low-middle income countries. https://www.preventionweb.net/files/54328_mappingtheroleofinsuranceinmanaging.pdf

21 SDPI (2018). Risk management practices of small farmers: a feasibility study for introducing R4 Rural Resilience Initiative in Punjab. Oxfam, WFP, SDPI and Government of the Punjab. http://sdpi.org/publications/files/Risk-Management-Practices-of-Small-Farmers(15-03-18).pdf

22 OECD webpage: Disaster risk financing. http://www.oecd.org/finance/insurance/disaster-risk-financing.htm

23 World Bank (2017). Financial Protection against Natural Disasters. Disaster Risk Financing and Insurance Program. https://financialprotectionforum.org/sites/default/files/Financial\%20Protection\%20against\%20Natural\%20Disas ter.pdf

24 InsuResilience Secretariat (2017). Concept Note - Shaping the InsuResilience Global Partnership: Consultation Draft. http://www.insuresilience.org/wp-content/uploads/2017/12/Consultation-Draft-ConceptNote-InsuResilience-Global-Partnership-Nov-3.pdf 
25 At least $\$ 580 \mathrm{~m}$, maybe more - see Note 3.

26 InsuResilience website. http://www.insuresilience.org/projects/

27 D.J. Clarke and S. Dercon (2016). Dull Disasters? How planning ahead will make a difference. Oxford University Press. https://global.oup.com/academic/product/dull-disasters$9780198785576 ? \mathrm{cc}=$ us\&lang=en\&. https://doi.org/10.1093/acprof:oso/9780198785576.001.0001

For discussion of some programmes that have failed, see for example C. Arce (2016). Comparative Assessment of Weather Index Insurance Strategies. Vuna Research Report. Vuna: Pretoria. http://www.vuna-africa.com/wp-content/uploads/2017/12/ComparativeAssessment-of-Weather-Index-Insurance-Strategies-Literature-Review.-Arce-C..pdf

28 InsuResilience website. http://www.insuresilience.org/about/

29 Purchasing Power Parity, which enables comparisons to be made across countries.

30 S. Hares (2017). Disaster-hit nations must rebuild better or risk losing insurance, experts say. Thomson Reuters, 13 October 2017. http://news.trust.org/item/20171013224152-o0l3s/

31 See Figure F.1 on p.46 of this World Bank document, which describes the process: http://documents.worldbank.org/curated/en/430141467229470955/pdf/106715-WP-P147454OUO-9-SRI-LANKA-D4web.pdf

32 Access to Insurance Initiative (2017). Exploring challenges in scaling up insurance as a disaster resilience strategy for smallholder farmers. Op. cit.

33 M. Taylor (2016). Risky Ventures: Financial Inclusion, Risk Management and the Uncertain Rise of Index-Based Insurance. In S. Soederberg (ed.) Risking Capitalism. ResearchGate pp.237-66. https://doi.org/10.1108/S0161-723020160000031013

34 See, for example: https://openknowledge.worldbank.org/handle/10986/24374; http://mddb.apec.org/Documents/2015/FMP/SEM1/15_fmp_sem1_011.pdf; http://blogs.worldbank.org/endpovertyinsouthasia/improving-pakistan-s-fiscal-resilience-naturaldisasters;

https://www.preventionweb.net/files/submissions/52669 acpeuresult5adrffy16aren.pdf; http://documents.worldbank.org/curated/en/951701497623912193/pdf/116342-WP-PUBLIC 52p-SWIO-RAFI-Summary-Report-2017-Publish-Version.pdf https://www.adb.org/sites/default/files/publication/227516/adbi-pb2017-1.pdf; http://documents.worldbank.org/curated/en/430141467229470955/pdf/106715-WP-P147454OUO-9-SRI-LANKA-D4web.pdf

This is despite the World Bank's commitment to mainstreaming citizen engagement in its operations:

http://documents.worldbank.org/curated/en/266371468124780089/pdf/929570WP0Box380ateg icFrameworkforCE.pdf

35 M. Kaika (2017). 'Don't call me resilient again!': the New Urban Agenda as immunology ... or ... what happens when communities refuse to be vaccinated with 'smart cities' and indicators. Environment \& Urbanization. Vol. 29(1): 89-102. https://doi.org/10.1177/0956247816684763

36 S. Khair (2015). Corruption Risks in National Climate Finance: The Bangladesh experience. Op. cit.

37 International Centre for Climate Change and Development (ICCCAD) website post: Climate Finance Transparency Mechanism (CFTM). http://www.icccad.net/climate-financetransparency-mechanism-cftm/

38 S. Khair (2015). Corruption Risks in National Climate Finance: The Bangladesh experience. Transparency International Bangladesh. https://carbonmarketwatch.org/wpcontent/uploads/2015/11/Corruption-risks-in-national-climate-finance-The-Bangladeshexperience.pdf

39 World Bank Independent Evaluation Group (IEG) (2012). Implementation Completion Report (ICR) Review - Haiti Catastrophe Insurance.

http://Inweb90.worldbank.org/oed/oeddoclib.nsf/DocUNIDViewForJavaSearch/8525682E00686 0378525788F006656AF?opendocument; World Bank IEG (2012). Implementation Completion Report (ICR) Review - OECS Countries - Catastrophe Insurance. http://documents.worldbank.org/curated/en/549471474511683088/pdf/000020051 20140624203806.pdf

40 M. Melecky and C. Raddatz. (2011). How Do Governments Respond after Catastrophes? Natural-Disaster Shocks and the Fiscal Stance. Policy Research Working Paper Series 3503. Washington DC: World Bank. https://doi.org/10.1596/1813-9450-5564. http://documents.worldbank.org/curated/en/202541468026361854/pdf/WPS5564.pdf

41 M. Norton et al (2014). Evidence of Demand for Index Insurance: Experimental Games and Commercial Transactions in Ethiopia. Journal of Development Studies. https://doi.org/10.1080/00220388.2014.887685

42 Access to Insurance Initiative (2017). Scaling Up Agricultural Index Insurance in Africa: Building disaster resilience of smallholder farmers. Op. cit. 
43 D. Clarke and R.V. Hill (2013). Cost-benefit analysis of the African Risk Capacity facility. IFPRI Discussion Paper 1292. Washington, DC: International Food Policy Research Institute. http://ebrary.ifpri.org/cdm/ref/collection/p15738coll2/id/127813. https://doi.org/10.2139/ssrn.2343159

44 N. Jensen et al. (2015). The Favourable Impacts of Index-Based Livestock Insurance: Evaluation results from Ethiopia and Kenya. ILRI Research Brief 52. https://cgspace.cgiar.org/bitstream/handle/10568/66652/ResearchBrief52.pdf?sequence=1

45 Economics of Climate Adaptation (2009). Shaping climate-resilient development: a framework for decision-making. http://media.swissre.com/documents/rethinking_shaping_climate_resilent_development_en.pdf

46 International Institute for Environment and Development (IIED) blog: Insuring against climate risk in Kenya. 6 June 2017. https://www.iied.org/insuring-against-climate-risk-kenya

47 World Bank IEG (2012). Implementation Completion Report Review - Haiti Catastrophe Insurance. Op. cit.

48 E. Biffis and E. Chavez (2017). Satellite Data and Machine Learning for Weather Risk Management and Food Security. Risk Analysis. Vol. 37, No. 8, 2017. http://onlinelibrary.wiley.com/wol1/doi/10.1111/risa.12847/full

49 See, for example: https://openknowledge.worldbank.org/handle/10986/24374; http://mddb.apec.org/Documents/2015/FMP/SEM1/15 fmp sem1 011.pdf; http://blogs.worldbank.org/endpovertyinsouthasia/improving-pakistan-s-fiscal-resilience-naturaldisasters;

https://www.preventionweb.net/files/submissions/52669 acpeuresult5adrffy16aren.pdf; http://documents.worldbank.org/curated/en/951701497623912193/pdf/116342-WP-PUBLIC52p-SWIO-RAFI-Summary-Report-2017-Publish-Version.pdf; https://www.adb.org/sites/default/files/publication/227516/adbi-pb2017-1.pdf; http://documents.worldbank.org/curated/en/430141467229470955/pdf/106715-WP-P147454OUO-9-SRI-LANKA-D4web.pdf

50 SADC (2017). Workshop report: Disaster risk management and financing workshop for SADC member states. 7-8 August 2017. Capital Empire Hotel, Johannesburg.

51 J. Kellett, A. Caravani and F. Pichon (2014). Financing disaster risk reduction: Towards a coherent and comprehensive approach. ODI and UNDP.

https://www.odi.org/sites/odi.org.uk/files/odi-assets/publications-opinion-files/9027.pdf

52 Access to Insurance Initiative (2017). Scaling up insurance as a disaster resilience strategy for smallholder farmers in Latin America. Briefing note from 11th Consultative Forum. https://a2ii.org/sites/default/files/reports/20180105_11thcf_briefing_note_final.pdf

53 M. Solana (2015). Making Public-Private Partnerships Work in Insurance. ILO. http://www.impactinsurance.org/sites/default/files/mp40_finalv.pdf

54 Oxfam (2018, forthcoming). The Dominican Republic's Eternal Debt to Disaster Prevention.

55 Oxford Policy Management (2018). Independent Evaluation of the African Risk Capacity (ARC): Annex C: Case Studies. http://www.opml.co.uk/projects/independent-evaluation-africanrisk-capacity

56 C. O'Brien et al. (2017). Shock-Responsive Social Protection Systems Research Synthesis Report. Oxford Policy Management. http://www.opml.co.uk/sites/default/files/OPM_Synthesis_Report_Shock_Responsive_SP.pdf

57 SADC (2017). Workshop report: Disaster risk management and financing workshop for SADC member states. Op. cit.

58 Personal communication with insurance expert practitioners, March/April 2018.

59 S. Surminski and D. Oramas-Dorta (2013). Do flood insurance schemes in developing countries provide incentives to reduce physical risks? https://www.cccep.ac.uk/wpcontent/uploads/2015/10/WP119-flood-insurance-schemes-developing-countries.pdf

60 See p.5, 'Unintended impacts': World Bank IEG (2012). Implementation Completion Report (ICR) Review - OECS Countries - Catastrophe Insurance. Op. cit.

61 Oxford Policy Management (2018). Independent Evaluation of the African Risk Capacity $(A R C)$ : Annex C Case studies. Op. cit.

62 P. O'Hare et al. (2017). Insuring we fail? Flood risk, vulnerability and the limits to 'bouncing back'. Town \& Country Planning. April 2017. http://www.waikato.ac.nz/staffprofiles/people/iainw/TCP_April17_insuring-we-fail.pdf

63 Defined by UNISDR as 'the use of the recovery, rehabilitation and reconstruction phases after a disaster to increase the resilience of nations and communities through integrating disaster risk reduction measures into the restoration of physical infrastructure and societal systems, and into the revitalization of livelihoods, economies and the environment'. https://www.preventionweb.net/english/professional/terminology/v.php?id=51750

64 IBRD/World Bank (2012). FONDEN: Mexico's Natural Disaster Fund - A Review. GFDRR. https://www.gfdrr.org/sites/default/files/publication/FONDEN_paper_M4.pdf https://doi.org/10.1596/26881 
65 Auditoria Superior de la Federación (2015). Evaluación núm. 1647: Evaluación de la Política Pública de Protección Civil.

https://www.asf.gob.mx/Trans/Informes/IR2014i/Documentos/Auditorias/2014_1647_a.pdf

66 G. Stargardter (2017). Cuts hurt Mexico quake response, outlook ahead of 2018 vote. Op. cit.

67 Mexico News Daily (2017). Will disaster funds go where they're needed? https://mexiconewsdaily.com/news/will-disaster-funds-go-where-theyre-needed/; Animal Politico (2018). Tarjetas de Bansefi para damnificados fueron hackeadas para sacar il dinero. https://www.animalpolitico.com/2018/01/tarjetas-hackeo-bansefi-robo-damnificados/

68 Government of Mexico (2010). Reglas Generales del Fondo de Desastres Naturales (FONDEN), publicadas el 3 de diciembre de 2010. See Article 28. https://www.gob.mx/shcp/documentos/reglas-generales-del-fondo-de-desastres-naturalesfonden-publicadas-el-3-de-diciembre-de-2010

69 See for example: S Cole et al (2014). How Does Risk Management Influence Production Decisions? Evidence from a Field Experiment. Harvard Business School Working Paper 13080. http://www.hbs.edu/faculty/Publication\%20Files/13-080_138f3c30-b5c2-4a97-bf569821f89fcbd3.pdf ; https://doi.org/10.2139/ssrn.2507978

F. de Nicola (2015). The impact of weather insurance on consumption, investment, and welfare. Quantitative Economics 6. http://onlinelibrary.wiley.com/doi/10.3982/QE300/abstract; https://doi.org/10.3982/qe300

M. Carter et al (2015). Where and how index insurance can boost the adoption of improved agricultural technologies. Journal of Development Economics 118 (2016) 59-71. https://www.sciencedirect.com/science/article/pii/S0304387815000991; https://doi.org/10.1016/j.jdeveco.2015.08.008

M. J. Miranda et al (2017). Insured loans increase credit access and farming technology adoption in Ghana. Innovation lab for assets and market access policy brief.

https://basis.ucdavis.edu/sites/g/files/dgvnsk466/files/2017-03/AMA\%20Brief\%20\%20Miranda\%20index\%20insured\%20loans\%20-\%202017-03_0.pdf. https://doi.org/10.2139/ssrn.2507978

70 J. Hansen et al. (2018). Climate risk management and rural poverty reduction. Agricultural Systems. https://www.sciencedirect.com/science/article/pii/S0308521X17307230?via=ihub. https://doi.org/10.1016/j.agsy.2018.01.019

71 Q Stoeffler et al (2016). Indirect protection: the impact of cotton insurance on farmers' income portfolio in Burkina Faso.

https://ageconsearch.umn.edu/bitstream/235980/2/Insurance_Burkina_AAEA_Quentin\%20Sto effler.pdf; and $\mathrm{H}$. N Isaboke et al (2016). The effect of weather index based micro-insurance on food security status of smallholders. Agricultural and resource economics. https://arejournal.com/are/article/view/40

72 S. Janzen and M. Carter (2017). After the Drought: The Impact of Microinsurance on Consumption Smoothing and Asset Protection. https://basis.ucdavis.edu/sites/g/files/dgvnsk466/files/2017-05/IBLI_impact_paper_v15b.pdf; and V. Bertram-Huemmer and K. Kraehnert (2015). Does Index Insurance Help Households Recover from Disaster? Evidence from IBLI Mongolia. https://ideas.repec.org/p/diw/diwwpp/dp1515.htm

73 J. Tobacman et al. (2017). Insuring farmers against weather shocks: evidence from India. 3ie Impact Evaluation Report 29. New Delhi: International Initiative for Impact Evaluation (3ie). http://www.3ieimpact.org/media/filer_public/2017/07/26/ie29-india-weather-insurance-web.pdf. https://doi.org/10.23846/OW31171

74 Well-being is measured by several metrics, including whether children have had enough to eat over the previous year, subjective assessments of the household's financial situation, how much control over life they feel they have and how much they believe that 'good things tend to happen to them'.

75 IPCC (2012). Managing the Risks of Extreme Events and Disasters to Advance Climate Change Adaptation. Special Report of the Intergovernmental Panel on Climate Change, p.322. https://www.ipcc.ch/pdf/special-reports/srex/SREX_Full_Report.pdf

76 Maladaptation refers to outcomes where action taken to reduce vulnerability produces the opposite effect for other systems, sectors or social groups.

77 S.R. Isakson (2015). Derivatives for development? Small-farmer vulnerability and the financialization of climate risk management. Journal of Agrarian Change. 15(4), 569-580. http://onlinelibrary.wiley.com/doi/10.1111/joac.12124/full. https://doi.org/10.1111/joac.12124

78 B. Müller, L. Johnson and D. Kreuer (2017). Maladaptive Outcomes of Climate Insurance in Agriculture. Global Environmental Change. Vol. 46, September 2017, pp.23-33. https://www.sciencedirect.com/science/article/pii/S0959378016304204. https://doi.org/10.1016/j.gloenvcha.2017.06.010

79 A. Fuchs and H. Wolff (2011). Concept and Unintended Consequences of Weather Index Insurance: The Case of Mexico. https://ideas.repec.org/p/iza/izadps/dp6234.html. https://doi.org/10.1093/ajae/aaq137

80 M. Solana (2015). Making Public-Private Partnerships Work in Insurance. Op. cit. 
81 Blog 'Don't call me resilient'. 28 August 2015. http://www.noladefender.com/content/dont-callme-resilient

82 N. Jensen and C. Barrett (2017). Agricultural Index Insurance for Development. Applied Economic Perspectives and Policy. Vol. 39, Issue 2, 1 June 2017. https://academic.oup.com/aepp/article/39/2/199/2528218/Agricultural-Index-Insurance-forDevelopment

83 D. Arias et al. (2014). Insuring Resilience: Mexico Case Study. World Bank.

84 R. Vargas Hill et al (2014). Using Subsidies for Inclusive Insurance: Lessons from Agriculture and Health. Microinsurance Paper No. 29. International Labour Organization. http://www.impactinsurance.org/sites/default/files/MP29.pdf

85 V. Tanzi and H. Zee (2001). Tax Policy for Developing Countries. International Monetary Fund. https://www.imf.org/external/pubs/ft/issues/issues27/

86 C. Churchill and M. Matul (eds) (2012). Protecting the poor: A microinsurance compendium. Volume II. International Labour Organization (ILO). http://www.ilo.org/wcmsp5/groups/public/--dgreports/---dcomm/---publ/documents/publication/wcms_175786.pdf

87 ActionAid (2016). Ten concerns about climate and disaster insurance schemes - and one rights-based alternative. http://www.actionaid.org/2016/05/ten-concerns-about-climate-anddisaster-insurance-schemes-and-one-rights-based-alternative

88 Webinar: 3-D Client Value Assessment. Impact Insurance Facility at ILO, Assets and Market Access Innovation Lab. USAID. 29 March 2018.

89 C. Averill and A. Marriott (2013). Universal health coverage: Why health insurance schemes are leaving the poor behind. Oxfam International. https://www.oxfam.org/sites/www.oxfam.org/files/bp176-universal-health-coverage-091013en_pdf

90 H. Greatrex et al. (2015). Scaling up index insurance for smallholder farmers: Recent evidence and insights. CCAFS Report No. 14, Copenhagen.

https://cgspace.cgiar.org/bitstream/handle/10568/53101/CCAFS Report14.pdf?sequence=1\&is Allowed=y

91 V. Bertram-Huemmer and K. Kraehnert (2015). Does Index Insurance Help Households Recover from Disaster? Evidence from IBLI Mongolia. https://ideas.repec.org/p/diw/diwwpp/dp1515.htm

92 H. Greatrex et al. (2015). Scaling up index insurance for smallholder farmers. Op. cit.

93 M. Taylor (2016). Risky Ventures: Financial Inclusion, Risk Management and the Uncertain Rise of Index-Based Insurance. Op. cit. https://doi.org/10.1108/S0161-723020160000031013

94 E. Bageant and C. Barrett (2015). Gender Differences in Demand for Index-Based Livestock Insurance. http://barrett.dyson.cornell.edu/files/papers/150424_BageantBarrett_Gender.pdf

95 'To the best of my knowledge, there are no studies that focus specifically on gender and demand for index insurance products.' From Bageant and Barrett (2015). Op. cit.

96 B. Müller, L. Johnson and D. Kreuer (2017). Maladaptive Outcomes of Climate Insurance in Agriculture. Op. cit. https://doi.org/10.1016/j.gloenvcha.2017.06.010

97 C. Delavallade et al. (2015). Managing Risk with Insurance and Savings: Experimental Evidence for Male and Female Farm Managers in the Sahel. Policy Research Working Paper 7176. World Bank. https://openknowledge.worldbank.org/bitstream/handle/10986/21393/WPS7176.pdf?sequence $=1 \&$ isAllowed=y. https://doi.org/10.1596/1813-9450-7176

98 ILO and Munich Re (2012). Protecting the poor: A microinsurance compendium. http://www.munichre-foundation.org/home/Microinsurance/MicroinsuranceCompendium.htm

99 M. Madajewicz et al. (2017). Managing Risks in Smallholder Agriculture: The Impacts of R4 on Livelihoods in Tigray, Ethiopia from 2012 to 2016. Oxfam External Evaluation. https://www.oxfamamerica.org/static/media/files/R4_Ethiopia_Impact_Evaluation_Report_2012 -2016_2yOZSeM.pdf

100 Dalberg Global Development Advisors (2016). Impact evaluation of the R4 Rural resilience initiative in Senegal. For WFP and Oxfam. https://www.oxfamamerica.org/static/media/files/WFP_Oxfam_R4_Final_Report_English_FINA L.pdf

101 A large body of research suggests that income in the hands of women, compared with men, is associated with larger improvements in child health and higher spending on health, housing and nutritious food. For an overview, see E. Duflo (2012). Women Empowerment and Economic Development. Journal of Economic Literature. 50(4), pp.1051-79.

102 Oxfam website: Helping Rice Farmers Cope with Natural Disaster: Weather Index Insurance. https://sri-lanka.oxfam.org/helping-rice-farmers-cope-natural-disaster-weather-index

103 M. Carter et al. (2017). Index Insurance for Developing Countries: A Reassessment. Annua Review of Resource Economics. http://www.annualreviews.org/doi/abs/10.1146/annurevresource-100516-053352 
$104 \mathrm{lbid}$.

105 Insurance Journal website. Growing Climate Risks May Be 'Impossible to Model' - and Ultimately Uninsurable. J. Shankleman. 13 November 2017.

https://www.insurancejournal.com/news/national/2017/11/13/470949.htm

106 IRI blog. 25,000 Insured Ethiopian Farmers Receive Payments for El Niño Droughts. Daniel Osgood. 1 July 2016. https://iri.columbia.edu/news/ethiopiar4drought/

107 DevPolicy blog. Is the Pacific Catastrophe Risk Insurance scheme an example of successful pooled service delivery? Tess Newton Cain. 8 April 2015. http://devpolicy.org/is-the-pacificcatastrophe-risk-insurance-scheme-an-example-of-successful-pooled-service-delivery20150408/

108 World Bank (2015). Country Note - Solomon Islands: Disaster risk financing and insurance. http://www.preventionweb.net/publications/view/49440

109 ActionAid (2017). The wrong model for resilience: How G7-backed drought insurance failed Malawi, and what we must learn from it. http://www.actionaid.org/publications/wrong-modelresilience-how-g7-backed-drought-insurance-failed-malawi-and-what-we-must-I

110 RMS blog. The Politics of Basis Risk. R. Muir-Wood. July 2017. http://www.rms.com/blog/2017/07/27/the-politics-of-basis-risk/

111 Jamaica Gleaner (2017). Jamaica Not Benefitting From Disaster Insurance Fund, MPs Seek Answers. 17 May 2017. http://jamaica-gleaner.com/article/news/20170517/jamaica-notbenefitting-disaster-insurance-fund-mps-seek-answers

112 IRI blog: 25,000 Insured Ethiopian Farmers Receive Payments for El Niño Droughts, by Daniel Osgood, 1 July 2016, https://iri.columbia.edu/news/ethiopiar4drought/

113 Oxfam website. Helping Rice Farmers Cope with Natural Disaster: Weather Index Insurance. Op. cit.

114 M. Carter et al. (2017). Index Insurance for Developing Countries: A Reassessment. Op. cit.

115 Oxfam (2013). Saving for Change: Financial inclusion and resilience for the world's poorest people. https://www.oxfamamerica.org/static/oa4/oxfam-america-sfc-ipa-bara-toplines.pdf

116 D. Collins et al. (2009). Portfolios of the Poor: How the world's poor live on $\$ 2$ a day. Op. cit.

117 Forty percent of BRAC clients are pre-approved and the amount of credit is limited (to $50 \%$ of the borrower's regular loan from BRAC). M. Carter et al. (2017). Index Insurance for Developing Countries: A Reassessment. Op. cit.

118 D. Collins et al. (2009). Portfolios of the Poor: How the world's poor live on $\$ 2$ a day. Op. cit. See also continuing work on Financial Diaries: http://financialdiaries.com/

119 DFID (2016). Business Case for investing in PCRAFI. iati.dfid.gov.uk/iati_documents/5546194.odt

120 World Bank (2017). Sovereign Catastrophe Risk Pools: World Bank Technical Contribution to the G20. https://openknowledge.worldbank.org/handle/10986/28311. https://doi.org/10.1596/28311

121 A. de Janvry et al. (2016). Weather Index Insurance and Shock Coping Evidence from Mexico's CADENA Program. World Bank Policy Research Working Paper 7715 http://documents.worldbank.org/curated/en/563971467994584299/Weather-index-insuranceand-shock-coping-evidence-from-Mexicos-CADENA-Program. https://doi.org/10.1596/1813 9450-7715

122 Oxford Policy Management (2018). Independent Evaluation of the African Risk Capacity (ARC): Formative Phase 1 Report. http://www.opml.co.uk/projects/independent-evaluation african-risk-capacity

123 ODI event: 'Building back better': a resilient Caribbean. Op. cit.

124 Start Network website. Drought risk financing. https://startnetwork.org/start-labs/drought-riskfinancing

125 World Bank (2013). Initial Market Assessment - Country Scoping Note: Haiti. Political Champions Group - Partnership for stimulating insurance penetration in lower income countries. http://documents.worldbank.org/curated/en/412761468189235456/pdf/98009-WPBox391499B-PUBLIC-PCG-Country-Note-Haiti-092213.pdf

126 Direct quote from an insurer, May 2017.

127 Access to Insurance Initiative (2017). Exploring challenges in scaling up insurance as a disaster resilience strategy for smallholder farmers. Op. cit.

128 InsuResilience website. http://www.insuresilience.org/about/

129 Contact Oxfam America for more details on this.

130 Oxfam (2013). Oxfam Policy on Program Evaluation. https://www.oxfam.org/sites/www.oxfam.org/files/oxfam-program-evaluation-policy-oct13.pdf 
131 D. Da Costa (2013). The 'rule of experts' in making a dynamic micro-insurance industry in India. The Journal of Peasant Studies. 40:5, 845-65.

http://www.tandfonline.com/doi/abs/10.1080/03066150.2013.857659. https://doi.org/10.1080/03066150.2013.857659

132 R. Kovacevic and G. Pflug (2004). Does insurance help to escape the poverty trap? - a ruin theoretic approach. https://www.jstor.org/stable/41350409?seq=1\#page_scan_tab_contents; and S. Hallegatte et al. (2016). Shock Waves: Managing the Impacts of Climate Change on Poverty. World Bank.

https://openknowledge.worldbank.org/bitstream/handle/10986/22787/9781464806735.pdf?seq uence $=13 \&$ is Allowed $=y$

133 World Bank (2013). Initial Market Assessment - Country Scoping Note: Haiti. Op. cit.

134 D.J. Clarke (2016). A Theory of Rational Demand for Index Insurance. American Economic Journal: Microeconomics 2016, 8(1): 283-306.

https://www.economics.ox.ac.uk/materials/working_papers/paper572.pdf. https://doi.org/10.1257/mic.20140103

135 S. Chantarat et al. (2016). Welfare impacts of index insurance in the presence of a poverty trap. PIER Discussion Paper 24; (https://doi.org/10.1016/i.worlddev.2016.12.044) and M. Carter and S. Janzen (2017). Social Protection in the Face of Climate Change: Targeting Principles and Financing Mechanisms. https://doi.org/10.1017/S1355770X17000407

R. Kovacevic and G. Pflug (2004). Does insurance help to escape the poverty trap? - a ruin theoretic approach. Op. cit. https://doi.org/10.1111/j.1539-6975.2010.01396.x

136 S. Janzen and M. Carter (2017) After the Drought: The Impact of Microinsurance on Consumption Smoothing and Asset Protection. https://basis.ucdavis.edu/sites/g/files/dgvnsk466/files/2017-05//BLI_impact_paper_v15b.pdf

137 Undertaken by Charles Stutley - internal for Oxfam.

138 ILO and IFC (2017). Unlocking Smallholder Credit: Does Credit-Linked Agricultural Insurance Work?

http://www.indexinsuranceforum.org/sites/default/files/ILO\%20report\%20English\%20low_res\% 2010 4.pdf

139 A. Stoppa and W. Dick (2018, forthcoming). Agricultural Insurance in Burkina Faso: Challenges and Perspectives. Report for Oxfam.

140 Oxfam (2017). Impact Evaluations of the R4 Rural Resilience initiative in Senegal (20132016): Oxfam Evaluation Summary. https://www.oxfamamerica.org/static/media/files/R4_Toplinev4.pdf

$141 \mathrm{P}$ Muhkerjee et al (2017). Bundling to make agriculture insurance work. http://www.impactinsurance.org/publications/mp47

142 Feed the Future Senegal Naatal Mbay. https:/www.rti.org/impact/feed-future-senegal-naatalmbay

143 M. Madajewicz et al. (2017). Managing Risks in Smallholder Agriculture: The Impacts of R4 on Livelihoods in Tigray, Ethiopia. Op. cit

144 Dalberg Global Development Advisors (2016). Impact evaluation of the R4 Rural resilience initiative in Senegal. Op. cit.

145 C. Arce (2016). Comparative Assessment of Weather Index Insurance Strategies. Vuna Research Report. http://www.vuna-africa.com/wp-content/uploads/2017/12/ComparativeAssessment-of-Weather-Index-Insurance-Strategies-Literature-Review.-Arce-C..pdf

146 G20 Hamburg Climate and Energy Action Plan for Growth, 2017. http://unepinquiry.org/wpcontent/uploads/2017/07/Climate_and_Energy_Action_Plan_for_Growth.pdf

147 World Bank IEG (2012). Implementation Completion Report Review - Haiti Catastrophe Insurance. Op. cit.

148 World Bank IEG (2012). Implementation Completion Report (ICR) Review - OECS Countries Catastrophe Insurance. Op. cit.

149 Personal communication with World Bank staff, November 2017.

150 Oxford Policy Management (2018). Independent Evaluation of the African Risk Capacity (ARC): Formative Phase 1 Draft Report. Op. cit.

151 A. de Janvry et al. (2016). Weather Index Insurance and Shock Coping Evidence from Mexico's CADENA Program. Op. cit. https://doi.org/10.1596/1813-9450-7715

152 lbid.

153 Extreme poverty is defined as a household whose income falls below the lowest income necessary to afford a minimum basket of food. Moderate poverty is defined as a household which cannot cover its expenses of food, health, education, clothing, home and public transportation.

154 D. Arias et al. (2014). Insuring Resilience: Mexico Case Study. World Bank.

155 lbid. 
156 Access to Insurance Initiative (2016). The role of mutuals, cooperatives and community-based organisations in inclusive insurance markets. 7th Consultative Forum, Briefing Note. https://a2ii.org/sites/default/files/reports/7th_consultative_forum_briefing_note.pdf

157 VisionFund (2018). Climate insurance fund launched for Africa and Asia. http://www.visionfund.org/217/media/news/article/climate-insurance-programme-launched-forafrica-and-asia/

158 S.O. Gönülal (2013). Takaful and Mutual Insurance: Alternative Approaches to Managing Risks. World Bank. https://openknowledge.worldbank.org/handle/10986/13087

159 ICMIF (2017). The missing chapter of microinsurance in India - a diagnostic of mutuals. https://www.icmif555.org/sites/default/files/India diagnostic complete report.pdf

160 ICMIF website: First-of-its-kind report highlights enormous potential for developing mutual and cooperative insurance for the poor in India. 17 July 2017. https://www.icmif.org/news/first-itskind-report-highlights-enormous-potential-developing-mutual-and-cooperative-insurance

161 World Bank (2013). Fondos: Mexico's Unique Agricultural Mutual Insurance Funds. Mexico Agriculture Insurance Market Review.

http://documents.worldbank.org/curated/en/197661468281079879/pdf/880990BRI0P1300uranc e04PagerOFondos.pdf

162 ADB (2016). Bangladesh: Developing Inclusive Insurance Sector Project. Implementation Completion Memorandum. https://www.adb.org/sites/default/files/projectdocument/189008/41671-022-icm.pdf

163 Conversation with Shaun Tarbuck, ICMIF chair. May 2017.

164 ADB (2016). Bangladesh: Developing Inclusive Insurance Sector Project. Op. cit.

165 ICMIF (2017). The missing chapter of microinsurance in India - a diagnostic of mutuals. Op. cit.

166 M. Solana (2015). Making Public-Private Partnerships Work in Insurance. Op. cit.

167 lbid.

168 See for example: Oxfam blog, by G. Charles: Putting the missing "p" in public-privatepartnerships: Lessons from the R4 Rural Resilience Initiative. 15 October 2015. https://politicsofpoverty.oxfamamerica.org/2015/10/putting-the-missing-p-in-public-privatepartnerships-lessons-from-the-r4-rural-resilience-initiative/

169 Government of Mexico and World Bank (2012). Improving the assessment of disaster risks to strengthen financial resilience: A Special Joint G20 Publication by the Government of Mexico and the World Bank.

http://documents.worldbank.org/curated/en/606131468149390170/pdf/709880WP0P13020BL C00GFDRR0G200High.pdf. https://doi.org/10.1596/26784

170 World Bank IEG (2013). Implementation Completion Report Review - CCRIF. http://documents.worldbank.org/curated/en/901861475092273503/pdf/00002005120140626080209.pdf

171 Oxford Policy Management (2018). Independent Evaluation of the African Risk Capacity $(\mathrm{ARC})$ : Formative Phase 1 Draft Report. Op. cit.

172 InterAmerican Development Bank (2017) Three are better than one: government, civil society, private sector. Joint efforts in Caribbean Countries toward sustainable development. https://publications.iadb.org/bitstream/handle/11319/8288/IDB_The_Caribbean_Web percent20 percent28004 percent29.pdf?sequence=1\&isAllowed $=y$

173 World Bank (2018). High-Level Forum Highlights Role of Adaptive Social Protection in Coping with Crisis and Building Resilience. http://www.worldbank.org/en/news/pressrelease/2018/02/15/high-level-forum-highlights-role-of-adaptive-social-protection-in-copingwith-crisis-and-building-resilience

174 Social protection is a basic right of all people, rooted in the Universal Declaration of Human Rights (articles 22 and 25) and the International Labour Organization (ILO) Convention 102 (1952) on Social Security (Minimum Standards).

175 ILO website: Social Protection Floor. http://www.ilo.org/secsoc/areas-of-work/policydevelopment-and-applied-research/social-protection-floor/lang--en/index.htm

176 ILO (2015) Guidelines for a just transition towards environmentally sustainable economies and societies for all. p16-17. http://www.ilo.org/wcmsp5/groups/public/---ed emp/--emp_ent/documents/publication/wcms_432859.pdf

177 ILO (2017). World Social Protection Report 2017-19: Universal social protection to achieve the Sustainable Development Goals. http://www.ilo.org/global/publications/books/WCMS 604882/lang--en/index.htm

178 S. Hallegatte et al. (2016). Shock Waves: Managing the Impacts of Climate Change on Poverty. Op. cit.; S. Hallegatte et al. (2017). Unbreakable: Building the Resilience of the Poor in the Face of Natural Disasters. Op. cit.; C. Del Ninno et al. (2016). Social Protection Programs for Africa's Drylands. World Bank. http://documents.worldbank.org/curated/en/736221471343475745/pdf/107854-PUB-PUBLICPUBDATE-8-9-16.pdf 
179 L. Ralston et al. (2017). The Impacts of Safety Nets in Africa: What Are We Learning? Op. cit. https://doi.org/10.1596/1813-9450-8255

180 C. Del Ninno et al. (2016). Social Protection Programs for Africa's Drylands, op. cit.

181 S. Hallegatte et al. (2016). Shock Waves: Managing the Impacts of Climate Change on Poverty. Op. cit.

182 O'Brien et al (2017). Shock-Responsive Social Protection Systems Research Synthesis Report. Op. cit. and ILO (2017) World Social Protection Report 2017-2019. Op cit (pp 188-9).

183 Global Facility for Disaster Reduction and Recovery (GFDRR)/World Bank (2016). Result Area 5. Africa Disaster Risk Financing Initiative: Activity Report 2014-16. Building Disaster Resilience in Sub-Saharan Africa Program.

https://www.preventionweb.net/files/submissions/52669_acpeuresult5adrffy16aren.pdf

184 O'Brien et al (2017). Shock-Responsive Social Protection Systems Research Synthesis Report. Op. cit.; Oxford Policy Management (2018). Independent Evaluation of the African Risk Capacity (ARC): Annex C: Case Studies. Op. cit.

185 D. Hugenbusch and T. Neumann (2016). Cost-Benefit analysis of disaster risk reduction: A synthesis for informed decision making. https://www.aktion-deutschland-hilft.de/fileadmin/fm$\mathrm{dam} / \mathrm{pdf} /$ publikationen/aktion-deutschland-hilft-studie-zur-katastrophenvorsorge-englischeversion-english-version.pdf

186 K. Wethli (2014). Benefit-Cost Analysis for Risk Management: Summary of Selected Examples. World Bank.

http://siteresources.worldbank.org/EXTNWDR2013/Resources/82580241352909193861/8936935-1356011448215/8986901-

1380568255405/WDR15_bp_BenefitCost_Analysis_for_Risk_Management_Wethli.pdf

187 Access to Insurance Initiative (2017). Scaling up insurance as a disaster resilience strategy for smallholder farmers in Latin America. Briefing Note, 11th Consultative Forum. https://a2ii.org/sites/default/files/reports/20180105_11thcf_briefing_note_final.pdf

188 J. Kellet and A. Caravani (2013). Financing Disaster Risk Reduction: A 20 year story of international aid. Op. cit.

189 UNEP (2016). The Adaptation Finance Gap Report 2016. United Nations Environment Programme (UNEP). Nairobi, Kenya.

http://web.unep.org/adaptationgapreport/sites/unep.org.adaptationgapreport/files/documents/a gr2016.pdf

190 OECD estimated adaptation finance to be around $16 \%$ of total climate finance in 2013/14 (annual average) which was \$57bn - this equates to around \$9bn for adaptation in 2013/14 (annual average).

OECD (2015), Climate finance in 2013-14 and the USD 100 billion goal. A report by the Organisation for Economic Co-operation and Development (OECD) in collaboration with Climate Policy Initiative (CPI). http://www.oecd.org/environment/cc/OECD-CPI-ClimateFinance-Report.htm

191 lbid.

192 S. Hallegatte et al. (2017). Unbreakable: Building the Resilience of the Poor in the Face of Natural Disasters. Op. cit.

193 lbid.

194 These measures were either first, second or third most impactful for 49, 38 and 33 (respectively) of the 55 countries.

195 Georgia, Jordan, Senegal and Yemen. 'Non-poor' is defined as the wealthier $80 \%$ of the population.

196 R. Pearl-Martinez (2017). Financing Women Farmers: The need to increase and redirect agriculture and climate adaptation resources. Oxfam. https://doi.org/10.21201/2017.0889

197 DailyO website: Can Modi government's crop insurance scheme really prevent farmer suicides? Nivedita Khandekar. 24 July 2017. https://www.dailyo.in/politics/tamil-nadu-farmersjantar-mantar-loan-waiver-crop-insurance-pmfby/story/1/18551.html

198 The Hindu: Farm suicides get attention of Supreme Court. K. Rajagopal. 30 April 2017. http://www.thehindu.com/news/national/debts-drug-abuse-alcoholism-crop-failure-monsoonform-the-common-reasons-for-farmers-suicides-across-13-states-agricultural-ministry-reporttells-sc/article18341228.ece

199 The Guardian: Thousands of farmer suicides prompt India to set up \$1.3bn crop insurance scheme. 14 January 2016. https://www.theguardian.com/world/2016/jan/14/india-thousands-offarmer-suicides-prompt-1bn-crop-insurance-scheme

200 The guaranteed price, fixed each year, offered by the government to protect agricultural producers against any sharp fall in farm prices due to bumper production years. 
201 T.S. Sathyanarayana Rao et al. (2017). Prevention of farmer suicides: Greater need for state role than for a mental health professional's role. Indian Journal of Psychiatry. 2017 Jan-Mar; 59(1): 3-5. https://www.ncbi.nlm.nih.gov/pmc/articles/PMC5419010/ https://doi.org/10.4103/psychiatry.IndianJPsychiatry_89_17

202 D. Da Costa (2013). The 'rule of experts' in making a dynamic micro-insurance industry in India. Op. cit. And A.S. Sheth (2017). Cultivating Risk: Weather Insurance, Technology and Financialization in India. PhD thesis, MIT.

203 S.N. Kumar (2015). Spread of Self Help Group (SHG) movement in Haryana (An Indian State): Review of developments and way forward. https://www.microfinancegateway.org/library/spread-self-help-group-movement-haryanaindian-state-review-developments-and-way-forward

204 M. Gash and K. Odell (2013). The Evidence-Based Story of Savings Groups: A Synthesis of Seven Randomized Control Trials. http://www.seepnetwork.org/filebin/pdf/resources/FINAL_Evidence-Based_Savings_Web.pdf

205 E. Noggle (2017). Overview: The SILC Financial Diaries. Expanding Financial Inclusion in Africa Research Project. Catholic Relief Services (CRS). http://efiafrica.crs.org/wpcontent/uploads/2017/11/SILC-FD-Brief_Nov62017_Final.pdf

206 L. Weingärtner, F. Picho and C. Simonet (2017). How self-help groups strengthen resilience: A study of Tearfund's approach to tackling food insecurity in protracted crises in Ethiopia. https://www.odi.org/sites/odi.org.uk/files/resource-documents/11625.pdf

207 World Bank website: Scaling up Women's Economic Empowerment in India. 20 June 2017. http://www.worldbank.org/en/news/feature/2017/06/20/scaling-up-womens-economicempowerment-india

208 J. Reeves and C McQuistan (2018, forthcoming). Can financial risk transfer build the resilience of the poorest? Practical Action.

209 AIG (2018) AIG 2017 Annual Report. http://annual.aig.com/ui/2017/docs/AIG-2017-FinalAnnual-Report.pdf

210 RMS (2017). Mapping the role of insurance in managing disaster losses: a study of low and middle income countries. Note that the full report (available on request from RMS contact PRTeam@rms.com) has different figures from the Summary (available here http://forms2.rms.com/DFID-Executive-Summary.html). The full report has been quoted here.

211 http://www.germanclimatefinance.de/2016/11/01/climate-finance-roadmap-leaves-much-roomimprovement-get-us-100-billion/?s=roadmap

212 E. Cameron et al. (2013). Climate Justice: Equity and Justice Informing a New Climate Agreement.

https://www.wri.org/sites/default/files/climate justice_equity_and justice informing_a new_cli mate_agreement.pdf

213 Blog. Climate insurance scheme targets women farmers in Africa, Asia. A. Whiting. Thomson Reuters Foundation. 18 January 2018. https://www.zilient.org/article/climate-insurancescheme-targets-women-farmers-africa-asia

214 At least $\$ 580 \mathrm{~m}$, maybe more - see note 3.

215 S. Hallegatte et al. (2017). Unbreakable: Building the Resilience of the Poor in the Face of Natural Disasters. Op. cit.

216 InterAmerican Development Bank (2017). Three Are Better Than One: Government, Civil Society, Private Sector. Joint efforts in Caribbean Countries toward sustainable development. https://publications.iadb.org/bitstream/handle/11319/8288/IDB_The_Caribbean_Web percent20 percent28004 percent29.pdf?sequence=1\&isAllowed $=y$ 


\section{OXFAM}

Oxfam is an international confederation of 20 organizations networked together in more than 90 countries, as part of a global movement for change, to build a future free from the injustice of poverty: Please write to any of the agencies for further information, or visit www.oxfam.org

Oxfam America (www.oxfamamerica.org)

Oxfam Australia (www.oxfam.org.au)

Oxfam-in-Belgium (www.oxfamsol.be)

Oxfam Brasil (www.oxfam.org.br)

Oxfam Canada (www.oxfam.ca)

Oxfam France (www.oxfamfrance.org)

Oxfam Germany (www.oxfam.de)

Oxfam GB (www.oxfam.org.uk)

Oxfam Hong Kong (www.oxfam.org.hk)

Oxfam IBIS (Denmark) (www.ibis-global.org)

Oxfam India (www.oxfamindia.org)

Oxfam Intermón (Spain) (www.oxfamintermon.org)

Oxfam Ireland (www.oxfamireland.org)

Oxfam Italy (www.oxfamitalia.org)

Oxfam Japan (www.oxfam.jp)

Oxfam Mexico (www.oxfammexico.org)

Oxfam New Zealand (www.oxfam.org.nz)

Oxfam Novib (Netherlands) (www.oxfamnovib.nl)

Oxfam Québec (www.oxfam.qc.ca)

Oxfam South Africa (www.oxfam.org.za) 